Document downloaded from:

http://hdl.handle.net/10251/99864

This paper must be cited as:

Domenech Carbo, MT.; Lee, Y.; Osete Cortina, L.; Martín Rey, S. (2015). Influence of plasticizer and biocide on the functional properties of gelatin-based adhesives used in painting consolidation. Journal of Adhesion Science and Technology. 29(17):1774-1795. doi:10.1080/01694243.2014.975999

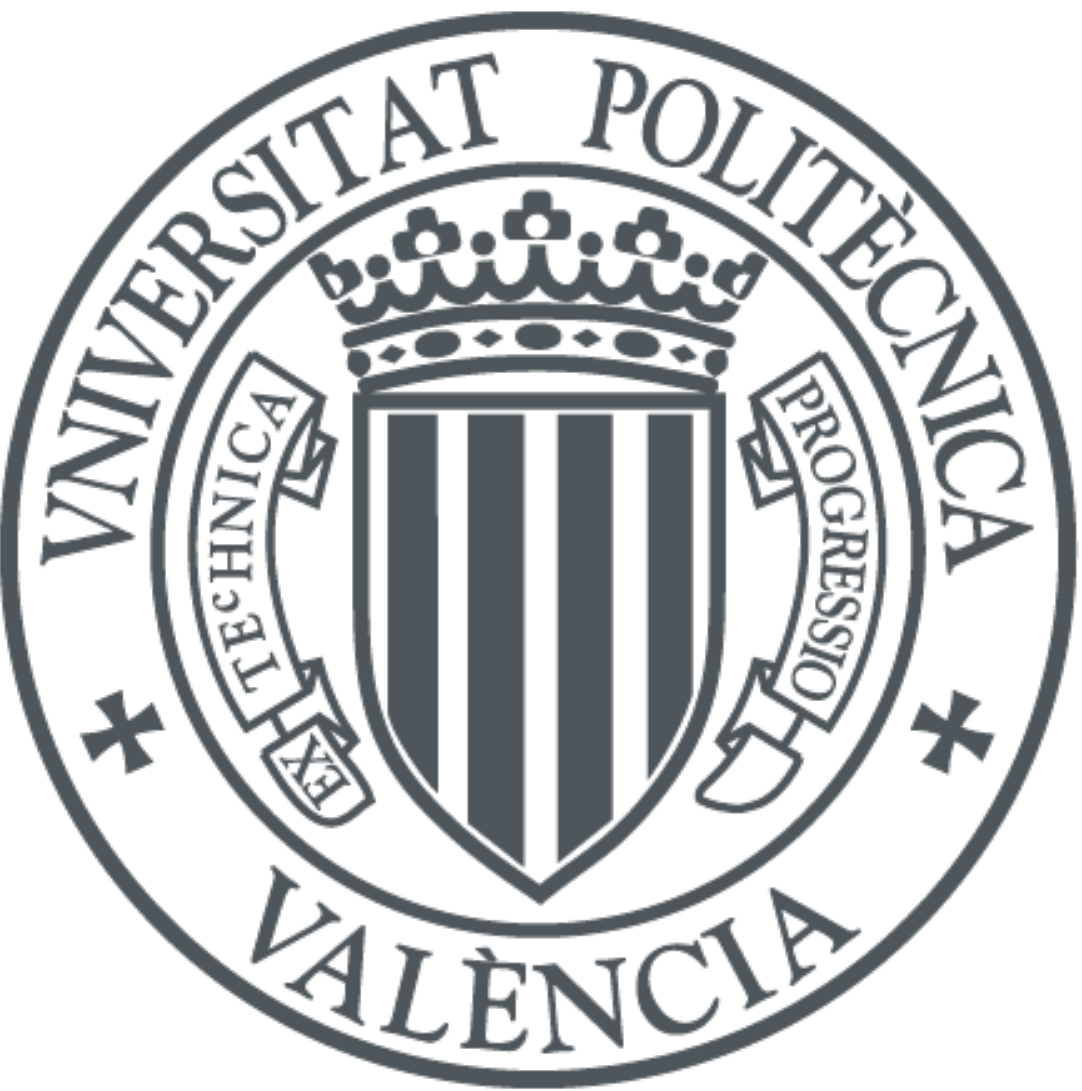

The final publication is available at

https://doi.org/10.1080/01694243.2014.975999

Copyright Taylor \& Francis

Additional Information 
Influence of the plasticizer and biocide on functional properties of gelatin-based adhesives used in the consolidation of paintings

María Teresa Doménech-Carbó*, Yu Lee, Laura Osete-Cortina, Susana Martín-Rey

Instituto Universitario de Restauración del Patrimonio. Universitat Politècnica de València, Valencia, Spain

* Instituto Universitario de Restauración del Patrimonio. Universitat Politècnica de València, Edificio 8B, Camino de Vera s/n, 46022-Valencia, Spain, email: tdomenec@crbc.upv.es 


\title{
Influence of the plasticizer and biocide on functional properties of gelatin-based adhesives used in the consolidation of paintings
}

\begin{abstract}
The study presented here focus on the influence of glycerol and citronella oil, added to gelatin dispersions as plasticizer and biocide, respectively, on the mechanical, water barrier and other functional properties of gelatin-based adhesives used in treatments of painting consolidation. For this purpose, ATRFTIR spectroscopy, gas chromatography-mass spectrometry (GC-MS), atomic force microscopy (AFM) analyses combined with tensile, water vapour permeability, water content and water solubility tests, have been performed on gelatin films prepared by adding glycerol and citronella oil. These two products have been chosen owing to their low toxicity and eco-friendly properties. Evaluation of the modification in the behaviour of the gelatin-based adhesives as consequence of the addition of glycerol and citronella oil has been carried out on the basis of the changes in microstructure of the adhesive and the changes in the three-dimensional structure of the protein molecules due to their interaction with glycerol and the citronella oil, all these data provided by the analytical techniques applied. In a second step, stability to the light of the proposed adhesive has been assessed in order to establish its suitability for painting consolidation. The results obtained suggest that citronella oil enhances the effectiveness of glycerol in improving mechanical and water barrier properties. Light ageing of specimens containing the proposed additives resulted in no remarkable changes in structure, mechanical, water barrier and other functional properties of the adhesives.
\end{abstract}

Keywords: glycerol, citronella oil, plasticizer, gelatin, painting, FTIR spectroscopy, GC-MS, AFM.

\section{Introduction}

Animal glue prepared by heating of collagen is the structural protein of connective tissues (skin, muscle tissue, tendons, bone and hide) in mammalian and fishes. Since ancient times this material has found wide application as strong adhesive for wood and fabric, as binding medium and as adhesive for paintings and grounds of easel paintings. Reports of the use of such material as medium of paintings (glue tempera) are found in 
a number of treatises dated back to the earlier centuries of the Middle Age worldwide (Europe and the Mediterranean Basin countries as well as in India, China and Japan). $[1-3]$

Gelatin, which is obtained by partial degradation of collagen, has gained attention for its abundance and biodegradability. Commercial gelatin is presented as a colorless or slightly yellow, transparent, brittle sheets, flakes or coarse powder. It swells up and absorbs 5-10 times its weight of water to form a gel in solutions below $30-40^{\circ} \mathrm{C}$. Gelatin is a hydrocolloid that consists of a heterogeneous mixture of water-soluble proteins of high average molecular mass that forms thermo-reversible films, which have found important applications in pharmaceutical,[4] food (confectionery, jellies, ice cream), as rubber substitutes, adhesives, photographic plates and films, matches and clarifying agent.[5] Gelatin is mainly composed of glycine and proline and contains remarkable amount of hydroxyproline. Aromatic amino acids tyrosine and phenylalanine are also present in low amount.

Use of gelatins (from mammalian and fishes) as consolidants and adhesives in conservation treatments performed on paintings has increased progressively in recent years due to the interest of conservators in replacing synthetic polymers by more ecofriendly materials.[6] Technical gelatin forms a three-dimensional network with zones of intermolecular microcrystalline junctions. Due to this microstructure, the dehydration of this system may result in an increase of the brittleness that, consequently, reduces the ability for consolidating of this material when is applied on a painting in a conservation treatment. This problem can be reduced by adding a plasticizer that increases workability and improves flow, extensibility and flexibility to the gelatin-based consolidant and reduces the risk of shrinking. 
Most commonly used plasticizers for biopolymers are polyols, mono-, di- and oligosaccharides. Among them, polyols (glycerol, propylene glycol, diethylene glycol and ethylene glycol) have been found to be particularly effective in plasticization of hydrophilic proteinaceous polymers such as gelatin.[7-16]

Plasticization results in lowering the glass-rubber transition temperature of the polymer, concomitant to the reduction of the viscosity, with a positive impact in the gas permeability of the film. It is attributed to a reorganization of the polymer network that results in a reduction of the intermolecular hydrogen bonding and an increase of the intermolecular spacing and chain mobility. [7]

Pinus oils of turpentine, destilled from the resin have been extensively used as solvents of varnishes based on diterpenoid and triterpenoid resins and drying oils. Oil of turpentine is composed of a variety of monoterpenoids among which $\alpha$ - and $\beta$-pinene are the major components. Besides them, other essential oils, composed of complex mixtures of monoterpenoids, have been used in the preparation of varnishes and paints at different extent and thus, a number of recipes including them can be found in old artists' treatises. In particular, camphor (Cinammomum camphorae Nees) has found use as plasticizer. $[3,17]$ Other essential oils such as clove oil (Syzygium aromaticum (L.), oil of spike (Lavandula spica DC) and oil of rosemary (Rosmarinus officinalis) have been mainly used as weak preservatives for paintings.[18] Additionally, their ability for slowly evaporating has been used for retarding the drying of the varnishes.[18] In general, biocide properties of essential oils are well known and thus, a number of studies can be found in recent literature in which the antioxidant and inhibitory 
properties $[19,20]$ as well as the fungicide [21-25] and antibacterial activity [26-28] of essential oils easily available commercially such as citronella, cedar lead and geranium is evaluated.

The study presented here focus on the evaluation of the influence of glycerol and citronella oil, added to gelatin dispersions as plasticizer and biocide, respectively, on the mechanical, water vapour barrier and other functional properties of gelatin-based adhesives used in treatments of painting consolidation. For this purpose, ATR-FTIR spectroscopy, gas chromatography-mass spectrometry (GC-MS), atomic force microscopy (AFM) analyses, tensile, water vapour permeability, water content and water solubility tests have been performed on gelatin films prepared by adding glycerol and citronella oil. These two products have been chosen owing to their low toxicity and eco-friendly properties. The study focuses on the evaluation of the modification in the behaviour of the gelatin-based adhesives as consequence of the addition of glycerol and glycerol-citronella oil. Discussion has been carried out on the basis of the changes in microstructure of the adhesive and the changes in the three-dimensional structure of the protein molecules due to their interaction with glycerol and the citronella oil, all these data provided by the analytical techniques applied. In a second step, photoresistance of the proposed adhesive has been assessed in order to establish its suitability for painting consolidation purposes.

\section{Experimental}

\section{Reagents and materials}

Technical gelatin of pure skin was purchased from CTS $®$ (Spain). This material is a glue of proteinaceous nature composed quite exclusively of collagen, obtained by 
grinding skins and other animal cartilaginous parts, soluble in water. Citronella oil (Cymbopongon nardus) was purchased from Anshin camphor oil, Ltd. (Hsingchu, Taiwan). Glycerol (1, 2, 3-Propanotriol) was purchased from Guinama ® (Spain).

\section{Preparation of test specimens}

Test specimens prepared as thin films were obtained from film forming dispersions of pure gelatin, gelatin plasticized with glycerol and gelatin plasticized with glycerol including citronella essential oil as biocide agent. Rectangular strips of dimensions (30x10) mm were prepared. Film thickness was measured with a micrometer with a sensitivity of $0.001 \mathrm{~mm}$. Five to ten thickness measurements were taken for each film, and the average was taken as the mean value. From these specimens were taken samples of specific dimensions for performing the different analyses and tests carried out in this study.

Three series of specimens were prepared. The first series was prepared by dispersing the gelatin in water with constant stirring at $80^{\circ} \mathrm{C}$. The concentration of proteins in the final film-forming solutions was $25(\mathrm{w} / \mathrm{w}) \%$ (specimen $\mathrm{A}$ ). Value of $\mathrm{pH}$ of all the gelatin aqueous solutions was $7 \pm 0.5$. A second series was prepared adding pure plasticizer to the gelatin solution so that the plasticizer:gelatin ratio was $0.51(\mathrm{w} / \mathrm{w})$ (specimen AG). The glycerol was added when the adhesive reaches $30^{\circ} \mathrm{C}\left( \pm 3{ }^{\circ} \mathrm{C}\right)$. The third series of specimens was prepared in the same way that second series by adding an amount corresponding to $1(\mathrm{w} / \mathrm{w}) \%$ of citronella to glycerol (specimen AGC). After addition of glycerol or glycerol-citronella emulsion to the gelatin solution, a new dispersion step was carried out for $15 \mathrm{~min}$ to remove air bubbles. The film-forming solution was then spread on a glass plate coated with a special sheet of polyacrylamide to facilitate the film recovery. After a drying period of 1 week, the film was peeled off 
the plate and equilibrated for 3 days in an environmental chamber under constant temperature and relative humidity conditions $\left(20^{\circ} \mathrm{C}\right.$; $\left.\mathrm{RH} 60 \%\right)$ before performing the analyses and tests.

\section{Instrumentation and testing methods}

\section{Gas chromatography-mass spectrometry}

A gas chromatograph Agilent 6890N (Agilent Technologies, Palo Alto, CA, USA) coupled to an Agilent 5973N mass spectrometer (Agilent Technologies) has been used. A capillary column HP-5MS (5\% phenyl-95\% methylpolysiloxane, 30 m, 0.25 mm i.d., $0.25 \mu \mathrm{m}$ film thickness, Agilent Technologies) was used in order to provide the adequate separation of components. The samples were injected in split mode (split ratio 1:20). The chromatographic conditions were as follows: initial temperature of $50{ }^{\circ} \mathrm{C}$ held for $15 \mathrm{~min}$ and then increased at $2{ }^{\circ} \mathrm{C} \cdot \mathrm{min}^{-1}$ up to $295^{\circ} \mathrm{C}$ held for $10 \mathrm{~min}$. Helium gas flow was set at $1.3 \mathrm{~mL} \cdot \mathrm{min}^{-1}$. The electronic pressure control was set to constant flow mode with vacuum compensation. Ions were generated by electron ionisation (70 $\mathrm{eV}$ ). The mass spectrometer was scanned from $\mathrm{m} / \mathrm{z} 20$ to $\mathrm{m} / \mathrm{z} 800$, with a cycle time of one second. An Agilent Chemstation software G1701CA MSD was used for GC-MS control, peak integration and mass spectra evaluation. Tuning of the mass spectrometer was checked using perfluoro-tributylamine. EI mass spectra were acquired by total ion monitoring mode. The temperatures of the interface and the source were 280 and $150^{\circ} \mathrm{C}$, respectively. Wiley Library of Mass Spectra and NIST were used for identifying compounds.

\section{$1.5 \mu \mathrm{L}$ of pure citronella unaged and light aged were injected in the GC-MS} system. 
FTIR spectroscopy

The IR spectra in the ATR mode of the films were obtained using a Vertex 70 (Bruker Optik GmbH, Germany) Fourier-transform infrared spectrometer with an FRDTGS (fast recovery deuterated triglycine sulphate) temperature-stabilised coated detector and a MKII Golden Gate Attenuated Total Reflectance (ATR) accessory. A total of 32 scans were collected at a resolution of $4 \mathrm{~cm}^{-1}$ and the spectra were processed using the OPUS 5.0/IR software (Bruker Optik GmbH, Germany).[29]

For performing the determination of the secondary structure of the gelatin proteins in the films, main features of the commonly used procedure including second derivative, Fourier Self-Deconvlution (FSD) and curve fitting analysis has been applied. [30-35] The position of overlapped IR bands that appear as shoulders of most intense bands in the IR absorption spectra were made to correspond to the frequency of the minima in the second derivative of the undeconvoluted spectra with a nine point Savitsky-Golay smoothing filter. [29,35] The selected band frequency values were further used as starting parameters for curve fitting analysis. In a second step, Fourier self-deconvolution (FSD) of the IR spectra covering amide I region (1595-1705 $\mathrm{cm}^{-1}$ ) was performed using Lorentzian line shape. Apodization with a Blackman-Harris function was always performed automatically at the same time in the software. FSD was performed using a bandwidth at half height of $13 \mathrm{~cm}^{-1}$ and a resolution enhancement factor of 2.4. These values, commonly used for quantitatively estimate the protein secondary structures, $[32,33,36,37]$ were selected in an attempt to avoid possible random noise artefacts indistinguishable from amide bands appearing in samples of gelatin. $[33,38]$ Prior to curve fitting, a straight base line passing through the ordinates at $1700 \mathrm{~cm}^{-1}$ and $1600 \mathrm{~cm}^{-1}$ was subtracted.[38] Curve fitting was performed in a third 
step. As previously mentioned, number and position of the fitted bands were taken from the second derivative spectrum. Levenberg-Marquardt algorithm was used for the curve fit of Lorentzian band shape profiles. This band shape function was used in this study as it yields slightly better results than Gaussian band shape function.[36] The base line was modified again by the least-squares curve-fitting program, which allows for a horizontal baseline to be adjusted as an additional parameter to obtain the best fit. The areas of all bands assigned to a given secondary structure were then summed up and divided by the total area. The number so obtained was taken to be the proportion of the gelatin protein chains in that conformation. [38]

\section{Atomic Force Microscopy}

A Multimode AFM (Digital Instruments VEECO Methodology Group, USA) with a NanoScope IIIa controller and equipped with a J type scanner (max scan size of 150x150x6 mm) was used. The topography of samples was studied in tapping mode. A silicon tip mounted on a cantilever (Bruker Tapping Mode etched silicon probes, model OTESPA-R3) with a spring constant of $\sim 26 \mathrm{~N} . \mathrm{m}^{-1}$ was used. Images were obtained using probe excitation frequencies of $300 \mathrm{kHz}$. All images were captured at a scan rate of $0.5-1 \mathrm{~Hz}$.

For performing the AFM morphological study, specimens were prepared by adapting the studied gelatin dispersions to the method previously described by DiazCalderón et al.[39] Solutions A, AG and AGC were diluted to $10^{-4} \mathrm{~g} . \mathrm{L}^{-1}$ in an attempt to obtain satisfactory resolution in images and then stored at $5^{\circ} \mathrm{C}$ for $48 \mathrm{~h}$. A small drop of the diluted dispersions was poured and extended to form a thin layer on the surface of a high oriented pyrolytic graphite plate (HOPG) with the help of a thin glass slide. After 
drying by Ar gas flown the sample was inserted in the AFM cell. For all samples, several images were recorded at different locations to verify the reproducibility of the observed features.

\section{Mechanical properties}

Tensile strength (TS), elongation to break (EB) and elastic modulus (EM) were measured on a microcomputer controlled electronic testing machine Deben-Gatan Microtest. Samples were conditioned at $22^{\circ} \mathrm{C}$ and $50 \pm 3 \%$ relative humidity in a desiccator containing magnesium nitrate saturated solution $\left(\mathrm{Mg}\left(\mathrm{NO}_{3}\right)_{2} \cdot 6 \mathrm{HNO}_{3}\right)$ for, at least, 2 days prior to analysis. The initial grip separation was set at $10 \mathrm{~mm}$, the rectangular strip had a length of $30 \mathrm{~mm}$, and a width of $10 \mathrm{~mm}$, and the crosshead speed was set at $0.4 \mathrm{~mm} \cdot \mathrm{min}^{-1}$. The mechanical parameters of the strips were measured in a static mode. The measurement was performed immediately when a sample was removed from the desiccators, measurements for each type of film were repeated at least three times, and the averages were taken as the results.

\section{Water vapour permeability (WVP)}

WVP of the films was determined gravimetrically in three replicate according to the ASTM E96-01 method. [40] The films were sealed with paraffin and O-ring rubber on glass cells which were $2 \mathrm{~cm}$ (o.d.), $2 \mathrm{~cm}$ (i.d.), $2 \mathrm{~cm}$ (depth) filled with silica gel. The cells were then placed in a desiccator containing saturated $\mathrm{Mg}\left(\mathrm{NO}_{3}\right)_{2} \cdot 6 \mathrm{HNO}_{3}$ solution $52 \% \pm 2 \mathrm{RH}$, which was maintained at $22^{\circ} \mathrm{C}$. The $\mathrm{RH}$ gradient was 50:0 (RH outside: RH inside of cells). The cells were weighed $( \pm 0.0001 \mathrm{~g})$ at intervals until the change in weight became constant. The $W V P$ was calculated with equation (1):

$$
W V P=(G / t) \cdot \delta l\left[A \rho_{o}\left(R H_{1}-R H_{2}\right)\right]
$$


Where $\delta$ is the average film thickness, $\rho_{o}$ is the vapour pressure of pure water $\left(22^{\circ} \mathrm{C}, 2.635 \mathrm{kPa}\right), A$ is the permeation area, $R H_{1}$ is the $\mathrm{RH}$ inside the chamber, $R H_{2}$ is the $\mathrm{RH}$ inside the cell and the term $G / t$ (g water/s) was calculated by linear regression from the weight variation over time data, in steady state.

\section{Water content (WC)}

According to literature [41] triplicate strips of (30x10) $\mathrm{mm}$ for each type of gelatin-based adhesives studied were weighed $\left(w_{1}\right)$, dried at $105^{\circ} \mathrm{C}$ for $24 \mathrm{~h}$, and weighted $\left(w_{2}\right)$ again. Water content $(W C)$ was determined as the percentage of initial film weight lost during drying and reported on a wet basis according to equation (2).

$$
W C(\%)=100\left(\mathrm{w}_{1}-\mathrm{w}_{2}\right) / \mathrm{w}_{1}
$$

Water solubility (WS)

This test is based on a reported method.[42,43] Triplicate strips of (30x10) mm for each type of gelatin-based adhesives studied were dried in oven at $100^{\circ} \mathrm{C}$ for $24 \mathrm{~h}$ until weight (w1) $( \pm 0.0001 \mathrm{~g})$ became constant. After this, the specimens were immersed in deionized water for $24 \mathrm{~h}$ followed by re-drying in oven at $100^{\circ} \mathrm{C}$ for $24 \mathrm{~h}$ and weighted again $\left(\mathrm{w}_{2}\right)$. Water solubility was calculated according to equation (3):

$$
\operatorname{WS}(\%)=100\left(w_{1}-w_{2}\right) /\left(w_{1}\right)
$$

\section{Accelerated light ageing}

In order to study the stability of the adhesives prepared from gelatin plasticized with glycerol and including citronella essential oil as biocide, specimens were light exposed. Light exposure tests were carried out in a QUV-BASIC model Q-Panel chamber with fluorescent Lamp Type UVA that emits $25 \mathrm{~W} . \mathrm{m}^{-2}$ at $300-400 \mathrm{~nm}$ 
$(115,000 \mathrm{~lx})$. The average temperature was $40^{\circ} \mathrm{C}$. RH was $35-40 \%$. Samples of the prepared specimens were irradiated for $100 \mathrm{~h}$ (A-UV, AG-UV and AGC-UV).

The behaviour of the polymers used as artists' media, adhesives and consolidants in paints is notably influenced by the characteristics of radiation to which these materials were exposed. For this reason, a UVA-type radiation source, close to sunlight spectrum, was selected. Thus, the photo-ageing test was performed in experimental conditions close to those to which the studied polychromies are subjected in indoor conditions.

The radiation exposure time of $100 \mathrm{~h}$ was chosen according to Feller's stability classification of materials.[44] Thus, the exposure dose to which specimens were subjected can be equated to the exposure doses on display in indoor conditions of a member material of Feller's stability "class A". According to Feller's model, the materials included in class A adequately maintain their properties up to 100 years. For establishing the light exposure time value in the accelerating ageing test, the corresponding exposure dose was equated to the equivalent value of dose in indoor environments, as previously reported in the literature, by following Bunsen and Roscoe's classical model [45] for the reciprocity principle. Thus, a "museum year" value of 100 was obtained as the equivalent to the artificial ageing dose reached after $100 \mathrm{~h}$, based on the indoor exposure dose value provided by Whitmore and Colaluca.[46] 


\section{Results and discussion}

\section{Effect of additives}

\section{FTIR spectroscopy}

Figure 1 shows the IR absorption spectra of specimens A and AGC that correspond to the films formed from pure gelatin and gelatin containing glycerol and citronella. The IR spectra show characteristic IR bands of gelatin films, which are also summarized in Table 1. The amide A band is broad and merges with methyl and methylene stretching bands. This broadening has been previously described as consequence of the intermolecular associations formed prevalently between low molecular gelatin fractions in high-temperature extracted gelatins or surviving crosslinks of the former collagen.[47] Some band associated to glycerol and citronella is recognized in the spectrum of specimen AGC at $1034 \mathrm{~cm}^{-1}\left(\mathrm{OH}\right.$ bend) and $1725 \mathrm{~cm}^{-1}$ $(\mathrm{C}=\mathrm{O}$ stretch), respectively. Additionally, a number of shoulders are also recognized in the gelatin bands that appear in the $3000-2800 \mathrm{~cm}^{-1}$ region, which are ascribed to the specific stretches of the hydrocarbon skeletons of glycerol and the monoterpenoid mixture that composes the citronella essential oil (vide infra). The lower intensity showed for amide III region, if compared with amide I and II bands, is associated with loss of triple helix state during thermal gelatin extraction.[47] Interestingly, increase of the intensity of the amide II band and small shift towards higher frequencies of the maximum of the amide I band are observed in the plasticized specimens AG and AGC. Amide I band, which dominates the IR spectrum, exhibits a broadening of its individual components indicative of a general disordering of the protein backbone. This disordering is probably due to the multiple stable conformations adopted by the protein upon dehydration.[48] The amide I band presents an asymmetric shape with maximum at $1627 \mathrm{~cm}^{-1} \cdot[32,47,49]$ This feature indicates that $\beta$-sheet conformation is prevalent in 
the gelatin films studied.[47,48,50] Plasticized specimens exhibit a band shift towards higher wavenumber $\left(1630 \mathrm{~cm}^{-1}\right)$. The displacement observed was related to the conformational changes undergone by the protein in the gelatin film in presence of glycerol and citronella monoterpenoids. Three prominent shoulders at ca 1660, 1652 and $1645 \mathrm{~cm}^{-1}$ are also observed in pure gelatin and plasticized specimens, which are associated with helical and random coil conformations.[32,47,49,50] These features suggest a noticeable contribution of the helical and random coil conformations in the protein structure of the formed films.

Use of glycerol as plasticizer of films from pigskin gelatin or pea proteins has also been reported recently.[16,42,51] It is interesting to note that, analogously to the values reported in the present study, maximum of amide I band in these studies was found at ca. 1632 and $1630 \mathrm{~cm}^{-1}$, respectively. Additionally, band ascribed to bend vibrations of $\mathrm{OH}$ group, that in pure glycerol occurs at $1036 \mathrm{~cm}^{-1}$ (data not shown), presents slight displacement in plasticised specimens, changing to $1034 \mathrm{~cm}^{-1}$ (see table 1). This shift has been related to the possible extra interactions that arise between the plastiziser and the protein molecules.[51,52]

Accurate study of the amide I band by means of mathematical treatment, which includes deconvolution followed by curve fitting, [32] provides information on secondary structure of proteins. Figure $2(a, b)$, shows the curve fitted Fourier self deconvoluted (FSD) spectra of amide I band for specimens A and AGC. The high number of individual bands that conforms the whole amide I band is indicative of the high degree of complexity of the secondary structure of the gelatin molecules. Frequency for each individual band position has been established from the second 
derivative spectra. Range of frequencies for each predominant conformation has been established according to literature.[30,32,33,35,47,50,53,54] Table 2 summarizes the calculated percent area contribution of the different amide I components for the films of pure and plasticized gelatin. According to Dong et al [54] and Prystupa and Donald [50] and taking into account prior seminal literature $[32,35,53,55]$ individual deconvoluted bands in the range $1611-1630 \mathrm{~cm}^{-1}$ and band at $1698 \mathrm{~cm}^{-1}$ have been assigned to protein aggregates and intermolecular $\beta$-sheet structures associated with $\beta$-turns with contribution of solvent-gelatin $\mathrm{H}$ bonds. Bands in the range $1631-1640 \mathrm{~cm}^{-1}$ are associated prevalently to intramolecular $\beta$-sheet conformations.[36] Bands in the range $1640-1650 \mathrm{~cm}^{-1}$ are associated prevalently with random coils and solvent-gelatin $\mathrm{H}$ bonds. Bands in the range $1650-1660 \mathrm{~cm}^{-1}$ are ascribed to random coils and helical conformations with contribution of $\beta$-turns whereas bands in the range $1661-1689 \mathrm{~cm}^{-1}$ are assigned to turns. As it can be seen in Table 2, the film A prepared from pure gelatin dispersion exhibits values higher than $50 \%$ area contribution for $\beta$-sheet conformation. Additionally, the low position of the maximum of the amide I band $\left(1627 \mathrm{~cm}^{-1}\right)$, the intense shoulder at $1620 \mathrm{~cm}^{-1}$ and the band at $1694 \mathrm{~cm}^{-1}$ confirm that forces in the hydrogen bonded planes of the $\beta$-sheet regions of the protein molecules are prevalently intermolecular and confirms that conformational changes, resulting in intermolecular association probably preceded of unfolding, have taken place at large extent during the drying of the film.[36,54]

Self-aggregation of proteins can take place during the drying of the proteinbased adhesive. The amount of water covering the surface of a protein in a fully hydrated state is around $0.3 \mathrm{~g} / \mathrm{g}$ protein, while the water content of a dried protein product is usually less than $10 \%$. Therefore, the drying process removes part of the 
hydration layer, which disrupts the native state of the protein and cause protein aggregation.[43] Dehydration induces conformational changes maximizing intra and inter chain hydrogen bonding in an attempt for compensating loss of hydrogen bonding interactions with water. Thus, the preferred conformation in the dried state is $\beta$-sheet regardless of the initial conformation in the aqueous solution as at low hydration levels. $\beta$-sheet conformation, which requires a lower degree of solvation, is energetically more favourable.[48] This has been attributed to the stronger dipole moment of alpha-helices than that of $\beta$-sheets. $[43,56]$

Addition of plasticizer and biocide has had a minimal effect on the IR spectra of both types of gelatin former solutions in concordance with prior studies focused on the effect of additives of polyalcohol type on drying of proteins. [48] In agreement with the up shift of the maximum of the amide I band $\left(1627\right.$ to $\left.1630 \mathrm{~cm}^{-1}\right)$, the AG and AGC glycerol-plasticized specimens exhibited a slight decrease in the percentage of area contributed by intermolecular $\beta$-sheet and helical and, conversely, an increase in the percentage of area contributed by random coil and turns (see Table 2). These changes could be indicative of a partial opening/unfolding of the ordered structure into random coils, turns and bends,[43] which should result in the spacing apart of the protein chains and the increase of the "free volume", and consequently, lowering the glass transition temperature for the adhesive and making it softer (vide infra). The results obtained are in agreement with reported use of glycerol to inhibit protein aggregation during refolding of proteins. $[57,58]$ or increase the folding yield of reduced proteins. $[59,60]$ As it can also be seen in Table 2, addition of low amount of citronella does not modify the trend exhibited by specimen AG in the percentage areas contributed by the different 
conformations. This result suggest that citronella at low concentration is not interfering glycerol to modify the gelatin film structure and hence, to plasticizing the film.

$G C-M S$

Chemical composition of commercial citronella oil has been characterized by gas chromatography-mass spectrometry. Main compounds identified are summarized in Table 3. Figure 3-a shows the chromatogram of citronella oil. Citronella oil is mainly composed of monoterpenoids that appear in the range 5-13 min. The main components are citronellal, $\beta$-citronellol, geraniol and citronellyl acetate. Geraniol acetate, dllimonene, linalool,eugenol, $\beta$-elemene, $\alpha$-muurolene, $\alpha$-cadinene, $\delta$-cadinene, naphthalene,1,2,4a,5,6,8a-hexahydro-4,7-dimethyl-1-(1-methylethyl)-, [1S$(1 \alpha, 4 \mathrm{a} \beta, 8 \mathrm{a} \alpha)]$-, elemol, germacrene D-4-ol, $\tau$-eudesmol, $\tau$-cadinol and $\alpha$-cadinol are present at moderate extent. Monoterpenoids also present at lower concentration are myrcene, $\alpha$-thujene, $\alpha$-pinene, camphene, $\beta$-phellandrene, $\alpha$-phellandrene, myrcene 2 $\beta$-pinene, among others. Mass spectra from these series of compounds are dominated by fragment ions with $\mathrm{m} / \mathrm{z}$ values of 41,55 and 69 , which are characteristic of direct and consecutive cleavage of allylic bonds in compounds containing aliphatic alkene chains such as myrcene, linalool, citronellal, citronellol or geraniol.[61] The results obtained are consistent with those other previously reported in literature corresponding to other botanical species of citronella oil.[62]

Plasticizers have been described, in general, as high boiling point compounds including linear or cyclic carbon chains of 14-40 carbons, with average molecular mass in the range 300-600. In the more particular case of biopolymers, in addition to water, the most commonly used pasticizers are polyols and oligosaccharides.[63] The GC-MS analysis performed on citronella oil confirms that this essential oil is a mixture of 
hydrocarbons, aldehides, ketones and alcohols with molecular mass in the range 46-222. Interestingly, most of the major compounds found in citronella oil are alcohols (citronellol, geraniol, elemol, linalool, eugenol). Therefore and, in coherence with the mechanical results obtained (vide infra), it could be assumed that these molecules should be contributing, at some extent, to plasticization of the gelatin films together with glycerol molecules.

\section{$A F M$}

Although the effects of polymer additives such as plasticizers have been studied over the past decades, a fundamental understanding of how these products affect the polymer properties is still incomplete. Free volume theories developed by FujitaDoolittle [64] and Ventras-Duda [65] are postulated for discussing mobilities of the solvent and chain segments in concentrated polymer solutions and thus, these models are applicable to the initial stages during the formation of the gelatin film. Deviations of the theoretical predictions related to the diffusion coefficient of small molecules (glycerol and complex mixture of citronella monoterpenoids) in the polymeric matrix of the drying films during the ultimate stages of the drying, could have taken place at some extent. On the other hand, blending in miscible components such as plasticizers impacts the nucleation and growth of crystalline spherical nuclei and the intermolecular links (hydrogen bonds, hydrophobic interactions and electrostatic repulsions) connecting these crystalline domains.[66,67] On these basis, it should be expected that the molecules of glycerol and citronella distribute between the gelatin chains and, preferably, form some kind of compatible microdomains, in the present study. Incompatibility between biopolymer and additive (glycerol or citronella) could generate, eventually, phase separation[63] and phase inversion processes at some extent.[68] 
Figure 4 shows topological graphs of precursor aqueous dispersions of specimens A, AG and AGC conveniently diluted at $10^{-4}$ g. $\mathrm{L}^{-1}$. HOPG has been chosen for this series of experiments as it is a hydrophobic substrate that could promote a faster release of water during fixing the gelatin by inert gas so that morphological changes of the gelatin dispersion in presence of additives as consequence of drying can be enhanced. Fig. 4-a shows features that are associated to rounded nuclei or crystalline domains formed by association of entangled gelatin chains strongly bonded.

Dimensions of rounded nuclei are in the range 200-20 nm with a maximum high of 9 $\mathrm{nm}$. Strands formed by a few single gelatin chains 100-20 nm long are identified which emerge from nuclei or connect them forming small chains. Addition of glycerol (Fig. 4b) results in a decrease of the average size of nuclei $(85-20 \mathrm{~nm})$ and a slight increase of their maximum high $(11 \mathrm{~nm})$. Increase of number of the strands emerging and connecting nuclei is also evident. Fig. 4-c shows the effect of the addition of citronella to the gelatin dispersion. Size of nuclei is maintained in the range 50-10 $\mathrm{nm}$ whereas the maximum high is increased to $14 \mathrm{~nm}$. A larger number of connected nuclei is observed in the image. Increase in the amount of nuclei connected by single strands observed in the gelatin dispersion plasticised with glycerol suggests that this last additive promotes the appearance of a network of interconnected nuclei that could be precursor structures of larger clusters conforming the dense gelatin-glycerol film. The smaller size of the nuclei forming the network and the highest degree of cross-linking observed in the specimen containing glycerol point out to structural differences responsible for the improvement in the functional properties observed in the plasticized specimen (vide infra). Addition of citronella to the plasticizer results in a reduction of the size of the interconnected nuclei of associated gelatin chains. These structural changes could also 
contribute to the observed changes in the functional properties of the gelatin films modified with the combination of plasticizer plus biocide.

Figure 5 shows the amplitude error channel graphs obtained after depositing a drop of A, AG and AGC aqueous dispersions onto a HOPG substrate. The significantly higher concentration of the precursor gelatin dispersions results in a continuous film deposited on the HOPG substrate in all cases. Nevertheless it is possible identify some features that protrude the film surface, which are associated to larger clusters of gelatin chains strongly entangled. Maximum diameter and high of these features are $1.2 \mu \mathrm{m}$ and $64 \mathrm{~nm}$, respectively, in A film, $1.0 \mu \mathrm{m}$ and $55 \mathrm{~nm}$ in AG film and $0.3 \mu \mathrm{m}$ and 17 nm for AGC film.

These results correlate with reported evidence that protein chains aggregate in the dilute regime by forming fractal structures. These aggregates have been described as clusters occluding solvent.[69] On the other hand the results presented here suggest that addition of plasticizer(biocide) improves the microscopic texture of the cast films by reducing the size of nuclei of entangled gelatin chains and thus promoting appearance of interstitial spaces between precursor nuclei during the coalescence phase.

\section{Mechanical Test}

Table 4 summarizes the values of elastic modulus (EM) obtained in the specimens prepared with pure gelatin (A), gelatin plasticized with glycerol (AG) and gelatin plasticized with glycerol including citronella (AGC). Film A prepared without addition of plasticizer exhibited high EM up to $14000 \mathrm{MPa} \cdot \mathrm{mm}^{-1}$. Glycerol has an important plasticizing effect on gelatin films that is characterized by a notable decrease in the EM value, as it can be seen by comparing the values of mechanical parameters 
obtained for specimens A and AG. Addition of citronella improved the plasticizing effect of glycerol as suggested by the slightly lower value of the elastic modulus obtained in specimen AGC. These results are in agreement with prior studies dealing with plasticization of protein films with glycerol.[9,12,15,16,42,51,70,71]

FTIR spectroscopy data obtained on the plasticized films of gelatin AG and AGC also support the mechanical results obtained. Plasticized specimens exhibited an up shift of the maximum of the amide I band from $1627 \mathrm{~cm}^{-1}$ to $1630 \mathrm{~cm}^{-1}$ together with a decrease in the percentage area contributed by $\beta$-sheet conformation and an increase in the percentage area contributed by random coil conformations, if their values are compared with the values from pure gelatin film A. These conformational changes can be associated with a larger scale three-dimensional changes involving unfolding of the molecules and decrease in the aggregation of gelatin chains. These changes correlate well with the effect of the small plasticizer molecules establishing new linkages with gelatin and occupying intermolecular spaces between polymer chains and thus resulting in a wider reorganization of the polymer network.[72] AFM experiments performed with A, AG and AGC gelatin dispersions and their diluted counterpart solutions could also support that mechanism. As it was previously described, addition of glycerol reduces the size of nuclei of entangled proteins and promotes the formation of a network of well interconnected small protein aggregates that should result in a more homogeneous three-dimensional network with increased interstitial spaces and flexibility at macroscopical scale.

\section{Water vapour permeability}

The $W V P$ of film samples prepared with pure gelatin (A) and blends of gelatinglycerol (AG) and gelatin-glycerol(citronella) (AGC) are shown in Table 4. The 
addition of glycerol caused an increase in the $W V P$ value of gelatin films in agreement with values previously reported in literature.[12,42,71,73] This is caused by the increase of free volume as consequence of the reorganization of the gelatin network. Interestingly, addition of citronella resulted in an additional increase in the $W V P$ thus confirming that compatible microdomains between gelatin glycerol and citronella molecules are mainly formed.

\section{Water content}

Analogously to $W V P$ values, the $W C$ values (see Table 4) obtained in plasticized gelatin films were higher than that found in pure gelatin film A. AGC specimen including citronella showed similar $W C$ value to that obtained for AG specimen.

\section{Water solubility}

This parameter is of great interest in the field of conservation of heritage. Reversibility of the adhesives applied to the painting in an intervention treatment is an important requirement. Thus, the highest solubility of the dried film, the better behavior as reversible adhesive. Analogously to previously barrier properties described, WS values for plasticized specimens AG and AGC were higher than that exhibited by pure gelatin film A.

\section{Light ageing}

\section{FTIR spectroscopy}

The most remarkable change in the IR spectra of the films after subjected them to UV irradiation is the decrease of the absorbance of the bands at $3300,3274,3070$ and $2853 \mathrm{~cm}^{-1}$, which are ascribed to the reduction of the content of $-\mathrm{CH}_{2}-\mathrm{N}=$ and 
$=\mathrm{CH}_{2}$ bonds in the gelatin main chain. These results suggest that, as previously reported [74], photodegradation of gelatin along its main chains, with scission of these bonds, is taking place at some extent in the gelatin. Decrease of band at $3450 \mathrm{~cm}^{-1}$, which is associated with loss of water bonded to gelatin, is also observed.

Aged specimen A-UV prepared from pure gelatin film-forming dispersion showed similar content of $\beta$-sheet percentage of band area contribution than specimen A. Slight decrease of the $\beta$-sheet percentage of band area contribution was found in plasticized films AG-UV and AGC-UV when these values were compared with those from the unaged counterparts as it is illustrated in Figure 6 where is shown, as an example, the Fourier self-deconvolution curve-fitting graphs for the $100 \mathrm{~h} \mathrm{UV}$ irradiated glycerol(citronella)-gelatin film (specimen AGC-UV). Therefore, in addition to the scission of protein chains, UV light ageing carried out in the conditions of the experiment seems to promote the partial conversion of short segment of gelatin to form other conformations in a similar way to that taking place in the gelation process. [75]

$G C-M S$

Due to the notable volatility of essential oils, a parallel study of compositional changes undergone by citronella oil during ageing has been carried out by gas chromatography-mass spectrometry. Main compounds identified are summarized in Table 3. Figure 3-b shows the chromatogram of citronella oil $100 \mathrm{~h}$ photoaged. In this chromatogram the monoterpenoid fraction in the range 5-13 min exhibits identical features than that from unaged citronella and, in general, relative proportion between main compounds is not significantly modified. Interestingly, a second terpenoid fraction is observed in the chromatogram of the irradiated sample of citronella, which appears in the range 14.5 to $17 \mathrm{~min}$. These compounds have been recognized as dimers formed 
from combination of monoterpenoids as result of the UV light irradiation. Mass spectra from these series of compounds, analogously to the compounds of the monoterpenoid fraction, are also dominated by fragment ions with $\mathrm{m} / \mathrm{z}$ values of 41,55 and 69 . Additionally, molecular ions with $\mathrm{m} / \mathrm{z}$ values of 290, 308 and 310 are also recognized whose $\mathrm{m} / \mathrm{z}$ value is exactly equal to the summation of molecular masses of $136+154$, $154+154$ and $156+154$, respectively, which correspond to the major monoterpenoids composing citronella oil (limonene, citronellal, citronellol, geraniol). Other involatile trimer, oligomer or polymer species probably have been formed during ageing, which owing to their higher molecular mass can not be detected by GC-MS. This finding suggests that polymerization of monoterpenoids from citronella oil probably could have taken place at some extent in the aged gelatin films. Similar polymerization processes have been reported for diterpenoid resins. [76]

\section{Mechanical test}

As reflected in Table 4, UV light irradiation results in no significative changes in the studied series of specimens. EM value of pure gelatin film A after UV light irradiating resulted unchanged. A slight decrease in the EM value of the plastiziced specimen AG-UV was found, compared with the unaged counterpart, whereas film AGC-UV exhibited a slight increase of EM.

The results obtained suggest that, in general, UV light ageing carried out in the conditions of the experiment seems to promote two opposite processes. Firstly, the scission of segments in protein chains with the consequent lowering of the average molecular weight of the protein molecules and the increase in stiffness. According to the results obtained in specimen A, this process seems not be dominating the 
mechanical behavior of ageing of gelatin films. On the other hand, the deaggregation of gelatin molecules, which should result in a loss of cross-linking in the gelatin network, could also take place. The latter is in good agreement with the FTIR spectroscopic data previously described that showed a decrease in the contribution of the $\beta$-sheet structures, associated to a decrease in the unfolding/aggregation of protein molecules in specimen AG-UV. Other processes associated with the addition of citronella should be considered for justifying the slight increase in stiffness observed in AGC-UV. Thus, the results provided by the GC-MS analyses indicate that polymerization of the main components of citronella takes place during UV light irradiation in parallel to evaporation of the most volatile components at some extent.

\section{Water vapour permeability}

The WVP of $100 \mathrm{~h}$ light aged films prepared with pure gelatin (A) and blends of gelatin-glycerol (AG) and gelatin-glycerol(citronella) (AGC) are also shown in Table 4. Values obtained in the UV-aged specimens were slightly lower than those exhibited by their unaged counterparts.

\section{Water content}

Analogously to WVP values, the WC values (see Table 4) obtained in the UV aged films were slightly lower than those exhibited by their unaged counterparts. Like in the unaged series of films, the plastiziced specimens AG and AGC exhibited higher WC values than A film.

\section{Water solubility}

Solubility of aged films was, in all cases, lower than that exhibited by the unaged ones as shown in Table 4. Nevertheless, decrease of WS values for plasticized 
specimens AG and AGC was lower than that exhibited by pure gelatin film A, in particular, for film AG. This result denotes a lesser loss of solubility properties on ageing and, hence, of reversibility for plasticized specimens.

\section{Conclusions}

In this paper has been presented a study on the effect of two specific additives, namely, glycerol and citronella oil, on several functional properties of gelatin-based adhesives used in painting conservation treatments. On the basis of prior studies of the effect of glycerol as plasticizer of gelatin films used for drug and food packaging, and studies on the capabilities of the citronella oil as low-toxic biocide, the study developed here has focused on evaluating the synergistic effects resulting on the combination of both additives incorporated at a suitable concentration in the gelatin adhesive dispersion. Spectroscopic and microscopy studies carried out indicate that combination of glycerol and citronella oil influences the process of formation of the gelatin film and its final properties and structure in a complex way. The results obtained here also confirm the excellent properties of glycerol as plasticizer of gelatin-based adhesives and indicate that citronella oil is not only acting as biocide but also is contributing, together with glycerol, to the improvement of the mechanical, water barrier and other functional properties of the adhesive.

Photoageing carried out in the present study, equivalent to 100 years of natural ageing of specimens containing the proposed additives, resulted in a slight increase of stiffness and slight loss of $W V P, W S$ and $W C$, thus denoting the high degree of photoresistance exhibited by the proposed gelatin-based adhesive. According with prior studies, main structural changes observed are related, in general, to changes in the three dimensional polymer network and, in particular, to changes in the secondary structure 
of gelatin molecules induced by the plasticizer, as suggested by the decrease in the $\beta$ sheet percentage of band area contribution found in the plasticized films. Small amounts of trimer, oligomer or polymer species, which should been formed from the main components of citronella oil during ageing could also contribute to structural changes in the polymeric network in the aged specimen containing citronella.

\section{Aknowledgements}

This work as been performed by members of the microcluster Grupo de análisis científico de bienes culturales y patrimoniales y estudios de ciencia de la conservación (Ref. 1362) belonging to the Valencia International Campus of Excellence. Financial support is gratefully acknowledged from the Spanish "I+D+I MICINN" projects CTQ2011-28079-CO3-01supported by ERDEF funds.

The authors wish to thank Mr. Manuel Planes and Dr. José Luis Moya, technical supervisors of the Electron Microscopy Service of the Universitat Politècnica de València.

\section{References}

[1] Cennini C. Il libro dell' arte [The Book of Art]. Vicenza: Akal; 1982.

[2] Gettens RJ, Stout GL. Painting materials. A short Encyclopaedia. New York: Dover; 1966.

[3] Mills JS White R. The Organic Chemistry of Museum Objects. London: Butterworths; 1987.

[4] Achet D, He XW. Determination of the renaturation level in gelatin films Polymer. 1995; 36: 787-791. 
[5] Jones NR. Uses of gelatin in edible products. In: Ward AG, Courts A, Editors. The Science and Technology of Gelatin, New York: Academic Press; 1997. p. 365-370.

[6] Vizárová K, Reháková M, Kirschnerová S, Peller A, Simoň P, Mikulášik R. Stability studies of materials applied in the restoration of a baroque oil painting. J. Cult. Herit. 2011; 12: $190-195$.

[7] Byun Y, Zhang Y, Geng X. Innovation in food packaging. (New York:

Academic press (Elsevier); 2014. Chapter 5. Plasticization and Polymer Morphology; p. 87-108.

[8] Vanin FM, Sobral PJA, Menegalli FC, Carvalho RA, Habitante AMQB.

Effects of plasticizers and their concentrations on thermal and functional properties of gelatin-based films, Food Hydrocolloids. 2005;19: 899-907.

[9] Audic J-L, Chaufer B. Influence of plasticizers and crosslinking on the properties of biodegradable films made from sodium caseinate. Eur. Polym. J. 2005; 41: 1934-1942. [10] Jongjareonrak A, Benjakul S, Visessanguan W, Tanaka M. Effects of plasticizers on the properties of edible films from skin gelatin of bigeye snapper and brownstripe red snapper, Eur. Food Res. Technol. 2006; 222: 229235.

[11] Lim L-T, Mine Y, Tung MA. Barrier and Tensile Properties of Transglutaminase Cross-linked Gelatin Films as Affected by Relative Humidity, Temperature, and Glycerol Content. J. Food Sci. 1999; 64: 616-622.

[12] Thomazine M, Carvalho RA, Sobral PJA. Physical properties of gelatin films plasticized by blends of glycerol and sorbitol. J. Food Sci. 2005; 70: 172-176.

[13] Jongjareonrak A, Benjakul S, Visessanguan W, Prodpran T, Tanaka M. Characterization of edible films from skin gelatin of brownstripe red snapper and bigeye snapper. Food Hydrocolloids. 2006; 20: 492-501. 
[14] Sobral PJA, Menegalli FC, Hubinger MD, Roques MA. Mechanical, water vapor barrier and thermal properties of gelatin based edible films. Food Hydrocolloids. 2001; 15: 423-432.

[15] Cuq B, Gontard N, Cuq J, Guilbert S. Selected functional properties of fish myofibrillar protein-based films as affected by hydrophilic plasticizers. J. Agr. Food Chem. 1997; 45: 622-626.

[16] Gueguen J, Viroben G, Noireaux P, Subirade M. Influence of plasticizers and treatments on the properties of films from pea proteins. Ind. Crops Prod. 1998; 7: 149157.

[17] Learner TJS. Analysis of Modern Paints, Los Angeles: The Getty Conservation Institute; 2004.

[18] Mayer R. Materiales y técnicas del arte [Materials and techniques of Art]. Madrid: Blume; 1993.

[19] Hsu, W-S, Yen J-H, Wang Y-S. Formulas of components of citronella oil against mosquitoes (Aedes aegypti). J. Environ. Sci. Health, Part B. 2013; 48: 1014-1019.

[20] Huang X-W, Feng Y-C, Huang Y, Li H-L. Chemical composition, antioxidant and the possible use as skin-care ingredient of clove oil (Syzygium aromaticum (L.) Merr. \& Perry) and citronella oil (Cymbopogon goeringii) from China. J. Essential Oil Res. 2013; 25: 315-323.

[21] Dawson-Andoh BE, Lovell R, Kamdem DP. Inhibitory and Compatibility Effects of Essential Oils on Sapstain and Biological Control Fungi. J. Essential Oil Res. 2000;12: 509-515.

[22] Yang VW, Clausen CA. Antifungal effect of essential oils on southern yellow pine, Int. Biodeter. Biodegr. 2007; 59: 302-306. 
[23] Tzortzakis NG, Economakis CD. Antifungal activity of lemongrass (Cympopogon citratus L.) essential oil against key postharvest pathogens. Innov. Food Sci. Emerg. Technol. 2007;8: 253-258.

[24] Khan MSA, Ahmad I, Biofilm inhibition by Cymbopogon citratus and Syzygium aromaticum essential oils in the strains of Candida albicans. J. Ethnopharmacol. 2012; $140: 416-423$

[25] De Billerbeck VG, Roques CG, Bessière J-M Fonvieille J-L, Dargent R. Effects of Cymbopogon nardus (L.) W. Watson essential oil on the growth and morphogenesis of Aspergillus niger. Can. J. Microbiol. 2001; 47: 9-17.

[26] Gonçalves TB, de Sousa EO, Rodrigues FFG, da Costa JGM. Chemical Composition and Antibacterial Evaluation of the Essential Oil from Cymbopogon winterianus Jowitt (Gramineae). J. Essential Oil Bearing Plants. 2010; 13: 426-431.

[27] Naik MI, Fomda BA, Jaykumar E, Bhat JA. Antibacterial activity of lemongrass (Cymbopogon citrates) oil against some selected pathogenic bacterias. Asia. Pac. J. Trop. Med. 2010; 3: 535-538.

[28] Skočibušić M, Bezić N, Dunkić V. Phytochemical composition and antimicrobial activities of the essential oils from Satureja subspicata Vis. growing in Croatia. Food Chem. 2006; 96: 20-28.

[29] Taddei P, Monti P. Vibrational infrared conformational studies of model peptides representing the semicrystalline domains of Bombyx mori silk fibroin. Biopolymers. 2005; 78: 249-258.

[30] Kong J. Yu S. Fourier Transform Infrared Spectroscopic Analysis of Protein Secondary Structures. Acta Biochim. Biophys. Sinica. 2007; 39: 549-559.

[31] Haris PI, Severcan F. FTIR spectroscopic characterization of protein structure in aqueous and non-aqueous media. J. Mol. Catal. B Enzym. 1999; 7: 207-221. 
[32] Byler, DM, Susi H. Examination of the Secondary Structure of Proteins by

Deconvolved FTIR Spectra. Biopolymers. 1986; 25: 469-487.

[33] Pelton JT, McLean LR. Spectroscopic Methods for Analysis of Protein Secondary

Structure. Anal. Biochem. 2000; 277: 167-176.

[34] Surewicz WK, Mantsch HH. New insight into protein secondary structure from resolution-enhanced infrared spectra. Biochim. Biophys. Acta. 1988; 952: 115-130. [35] Dong A, Huang P, Caughey WS. Protein Secondary Strucutres in Water from Second-Derivative Amide I Infrared Spectra. Biochemistry.1990; 29: 3303-3308. [36] Hu X, Kaplan D, Cebe P. Determining Beta-Sheet Crystallinity in Fibrous Proteins by Thermal Analysis and Infrarred Spectroscopy. Macromolecules. 2006; 39: 61616170.

[37] Rajkhowa R, Hu X, Tsuzuki T, Kaplan DL, Wang X. Structure and Biodegradation Mechanism of Milled Bombyx mory Silk. Biomacromolecules. 2012; 13: 2503-2512.

[38] Goormaghtigh E, Gasper R, Bénard A, Goldsztein A, Raussens V. Protein secondary structure content in solution, films and tissues: Redundancy and complementarity of the information content in circular dichroism transmission and ATR FTIR spectra. Biochim. Biophys. Acta. 2009; 1794: 1332-1343.

[39] Díaz-Calderón P, Caballero L, Melo F, Enrione J. Molecular configuration of gelatin water suspensions at low concentration. Food Hydrocolloids. 2014; 39: 171-179. [40] ASTM, Standard test method for water vapor transmission of materials. Annual books of ASTM Standards. Designation E 96-01. Philadelphia: ASTM, American Society for Testing Materials. 2001. 
[41] Rhim JW, Gennadios A, Weller CL, Hanna MA. Sodium dodecyl sulfate treatment improves properties of cast films from soy protein isolate. Ind. Crops Prod. 2002; 15: 199-205.

[42] Nur Hanani ZA, McNamara J, Roos YH, Kerry JP. Effect of plasticizer content on the functional properties of extruded gelatin-based composite films. Food Hydrocolloids. 2013; 31: 264-269.

[43] Wang L, Holmes J, Kerry JP. Assessment of film-forming potential and properties of protein and polysaccharide-based biopolymer films. Int. J. Food Sci. Technol. 2007; 42: 1128-1138.

[44] Feller RL. Accelerated Ageing. Photochemical and Thermal Aspects. Michigan: Dinah Berland; 1994.

[45] Bunsen RW, Roscoe HE. Photochemical researches. Part IV. Philos. Trans. R. Soc. Lond. 1859; 149: 879-926.

[46] Whitmore PM, Colaluca VG. The natural and accelerated aging of an acrylic artists' medium. Stud. Conserv. 1995; 40: 51-64.

[47] Muyonga JH, Cole CGB, Duodu KG. Fourier transform infrared (FTIR) spectroscopic study of acid soluble collagen and gelatin from skins and bones of young and adult Nile perch (Lates niloticus). Food Chem. 2004; 86: 325-332.

[48] Prestrelski SJ, Tedeschi N, Arakawa T, Carpenter JF. Dehydration-induced Conformational Transitions in Proteins and Their Inhibition by Stabilizers. Biophys. J. 1993; 65: 661-671.

[49] Hashim DM, Che Man YB, Norakasha R, Shuhaimi M, Salmah Y, Syahariza ZA, Potential use of Fourier transform infrared spectroscopy for differentiation of bovine and porcine gelatins. Food Chem. 2010; 118: 856-860. 
[50] Prystupa DA, Donald AM. Infrared study of gelatin conformations in the gel and sol states. Polym. Gels Networks. 1996; 4: 87-110.

[51] Bergo P, Sobral PJA. Effects of plasticizer on physical properties of pigskin gelatin films. Food Hydrocolloids. 2007; 21: 1285-1289.

[52] Sobral PJA, Menegalli FC, Hubinger MD, Roques MA. Mechanical, water vapor barrier and thermal properties of gelatin based edible films. Food Hydrocolloids. 2001; 15: $423-432$.

[53] Payne KJ, Veis A. Fourier Transform IR Spectroscopy of Collagen and Gelatin Solutions: Deconvolution of the Amide Iband fir Conformational Studies. Biopolymers. 1988; 27: 1749-1760.

[54] Dong A, Prestrelski SJ, Allison SD, Carpenter JF. Infrarred Spectroscopic Studies of Lyophilization- and Temperature-Induced Protein Aggregation. J. Pharm. Sci. 1995; 84: 415-424.

[55] Clark AH, Saunderson DPH, Suggett A. Infrared and laser-Raman spectroscopic studies of thermally-induced globular protein gels. Int. J. Pept. Protein Res. 1981; 17: 353-364.

[56] Sassi P, Giugliarelli A, Paolantoni M, Morresi A, Onori G. Unfolding and aggregation of lysozyme: A thermodynamic and kinetic study by FTIR spectroscopy. Biophys. Chem. 2011; 158: 46-53.

[57] Hevehan D, De Bernardez-Clark E. Oxidative renaturation of lysozyme at high concentrations. Biotechnol. Bioeng. 1997; 54: 221-230.

[58] Rariy RV, Klibanov AM,. Correct protein folding in glycerol. Proc. Natl. Acad. Sci. U.S.A. 1997; 94: 13520-13523. 
[59] MaedaY, Ueda T, Imoto T. Effective renaturation of denatured and reduced immunoglobulin G in vitro without assistance of chaperone. Protein Eng. 1996; 9: 95100.

[60] Maeda Y, Yamada H, Ueda T, Imoto T. Effect of additives on the renaturation of reduced lysozyme in the presence of 4 m urea. Protein Eng. 1996; 9: 461-465.

[61] Gross JH. Mass Spectrometry. Berlin: Springer; 2004.

[62] Millezi AF, Cardoso MG, Alves E, Hilsdorf Piccoli R. Reduction of Aeromonas hidrophyla biofilm on stainless stell surface by essential oils. Braz. J. Microbiol. 2013; 44: 73-80.

[63] Gurgel Adeodato Vieira M, Altenhofen da Silva M, Oliveira dos Santos L, Masumi Beppu M. Nautal-based plasticizers and biopolymer films: A review. Eur. Polym. J. 2011; 47: 254-263.

[64] Fujita H. Notes on Free Volume Theories. Polym. J. 1991; 23: 1499-1506.

[65] Vrentas JS, Vrentas CM, Duda JL. Comparison of Free-Volume Theories. Polym. J. 1993; 25: 99-101.

[66] Fowler JN, Chapman BR, Green DL. Impact of plasticizers and tackifiers on the crystallization of isotactic poly(1-butene). Eur. Polym. J. 2010; 46: 568-577. [67] Xu J, Li T-D, Tang X-L, Qiao C-D-, Jiang Q-W. Effect of aggregation behavior of gelatin in aqueous solution on the grafting density of gelatin modified with glycidol. Colloid Surf. B: Biointerfaces. 2012; 95: 201-207.

[68] Paiva A, Foster MD, Von Meerwall ED. Mobility of a tackifying resin in a pressure-sensitive adhesive. J. Polym. Sci. B Polym. Phys. 1998: 36: 373-381. [69] Ramzi A, Sutter M, Hennink WE, Jiskoot W. Static light scattering and smallangle neutron scattering study on aggregated recombinant gelatin in aqueous solution. J. Pharm. Sci. 2006; 95: 1703-1711. 
[70] Galieta G, Di Gioia L, Guilbert S, Cuq BJ. Mechanical and Thermomechanical Properties of Films Based on Whey Proteins as Affected by Plasticizer and Crosslinking Agents. Dairy Sci. 1998; 81: 3123-3130.

[71] Rocha Plácido Moore G, Marteilli SM, Gandolfo C, do Amaral Sobral PJ, Borges Laurindo J. Influence of the glycerol concentration on some physical properties of feather keratin films. Food Hydrocolloids. 2006; 20: 975-982.

[72] Wypych G. Handbook of plasticizers. Toronto: Chem.Tec. Publishing. 2004. [73] Cao N, Yang X, Fu Y. Effects of various plasticizers on mechanical and water vapor barrier properties of gelatin films. Food Hydrocolloids. 2009; 23: 729-735. [74] Kamińska A, Sionkowska A, Effect of UV radiation on the infrared spectra of collagen. Polym. Degrad. Stab. 1996;51: 19-26.

[75] Ross-Murphy SB. Structure and rheology of gelatin gels: recent progress. Polymer. 1992; 33: 2622-2627.

[76] Scalarone D, Lazzari M, Chiantore O. Ageing behviour and analytical pyrolysis characterisation of diterpenic resins used in art materials: Manila copal and sandarac. J. Anal. Appl. Pyrolysis. 2003; 68-69: 115-136. 


\section{Table captions}

Table 1. IR absorption bands and assignments for untreated gelatin specimen A and plasticized specimens AG and AGC.

Table 2. Percent area contribution of amide I components for untreated gelatin specimen A and plasticized specimens AG and AGC. Position of individual bands from second derivative spectra, in agreement with literature. [30,32,33,35,47,50,53,54]

Table 3. Main compounds identified by GC-MS in the samples of commercial unaged citronella (C) and $100 \mathrm{~h}$ UVA light aged (C-UV) together with molecular weight, retention time and main fragment ion identified in the mass spectra (base peak underlined).

Table 4. Mean value and standard deviation of elastic modulus $(E M)$, water vapour permeability $(W V P)$, water solubility $(W S)$, and water content $(W C)$ obtained in the studied specimens. 


\section{Figure captions}

Figure 1. IR absorption spectra of specimens A (bottom) and AGC (top) that correspond to the film of gelatin and gelatin containing glycerol with $1 \%$ citronella oil.

Figure 2. (a) Amide I curve fitted band for specimen A prepared from pure gelatin dispersion with fitted band components. Assignment of individual bands: ( $\beta$ ) $\beta$-sheet: 1612, 1619, 1626, 1634 and $1695 \mathrm{~cm}^{-1}$. (rc) random coil and helical: 1640, 1645 and $1652 \mathrm{~cm}^{-1} .(\alpha)$ triple helical: $1660 \mathrm{~cm}^{-1}$. (t) turns: $1668,1674,1682$ and $1689 \mathrm{~cm}^{-1}$. (b) Amide I curve fitted band for specimen AGC prepared from gelatin-glycerol with $1 \%$ citronella dispersion with fitted band components. Assignment of individual bands: $(\beta)$ $\beta$-sheet: 1612, 1619, 1624, 1629, 1634 and $1693 \mathrm{~cm}^{-1}$. (rc) random coil and helical: 1640, 1645, 1652 and $1657 \mathrm{~cm}^{-1} .(\alpha)$ triple helical: $1661 \mathrm{~cm}^{-1}$. (t) turns: 1668,1674 , $1682,1689 \mathrm{~cm}^{-1}$. Residual RMS error of curve fitting less than 0.006 .

Figure 3. Chromatogram of: a) citronella oil b) citronella oil photoaged $100 \mathrm{~h}$.

Figure 4. Amplitude error channel graphs that illustrate typical structures obtained after depositing a drop of aqueous dispersion previously aged $48 \mathrm{~h}$ at $5^{\circ} \mathrm{C}$, onto a $\mathrm{HOPG}$ substrate kept at $22^{\circ} \mathrm{C}$ : a) gelatin dispersion $\left(10^{-4}\right.$ g. $\left.\mathrm{L}^{-1}\right)$; b) gelatin-glycerol dispersion $\left(10^{-4}\right.$ g. $\left.\mathrm{L}^{-1}\right)$; c) gelatin-glycerol with $1 \%$ citronella dispersion $\left(10^{-4}\right.$ g. $\left.\mathrm{L}^{-1}\right)$.

Figure 5. Amplitude error channel graphs that illustrate typical structures obtained after depositing a drop of aqueous dispersion, previously aged $48 \mathrm{~h}$ at $5^{\circ} \mathrm{C}$, onto a HOPG substrate kept at $22^{\circ} \mathrm{C}$ : a) gelatin dispersion $\mathrm{A}$; b) gelatin-glycerol dispersion $\mathrm{AG}$; c) gelatin-glycerol with $1 \%$ citronella dispersion AGC. 
Figure 6. Amide I curve fitted band for specimen AGC-UV prepared from UV-aged specimen AGC with fitted band components. Assignment of individual bands: ( $\beta) \beta$ sheet: 1612, 1619, 1624, 1629, 1635 and $1693 \mathrm{~cm}^{-1}$. (rc) random coil and helical: 1640, $164516521657 \mathrm{~cm}^{-1} .(\alpha)$ triple helical: $1661 \mathrm{~cm}^{-1}$. (t) turns: 1668, 1674, 1682 and $1689 \mathrm{~cm}^{-1}$. Residual RMS error of curve fitting less than 0.006 . 
Table 1

\begin{tabular}{|c|c|c|c|}
\hline \multicolumn{3}{|c|}{$\begin{array}{l}\text { Frequency } \\
\left(\mathrm{cm}^{-1}\right)\end{array}$} & \multirow[t]{2}{*}{ Assignment } \\
\hline $\mathbf{A}$ & AG & AGC & \\
\hline 3450 & 3450 & 3450 & Bond water \\
\hline- & - & $3400^{\text {sh }}$ & OH stretch (citronella) \\
\hline- & $3300^{\text {sh }}$ & $3300^{\mathrm{sh}}$ & OH stretch (glycerol) \\
\hline 3274 & 3274 & 3274 & Amide A, N-H stretch \\
\hline 3070 & 3070 & 3070 & $\begin{array}{l}\text { Amide B, N-H Fermi resonance between amide II overtone and N-H } \\
\text { stretch }\end{array}$ \\
\hline 2957 & 2957 & 2957 & Antisymmetric stretch $\mathrm{CH}_{3}$ \\
\hline- & $2934^{\text {sh }}$ & $2934^{\text {sh }}$ & Antisymmetric stretch $\mathrm{CH}_{3}$ (glycerol) \\
\hline- & - & $2925^{\text {sh }}$ & Antisymmetric stretch $\mathrm{CH}_{2}$ (citronella) \\
\hline 2923 & 2923 & 2923 & Antisymmetric stretch $\mathrm{CH}_{2}$ \\
\hline- & - & $2913^{\text {sh }}$ & Antisymmetric stretch $\mathrm{CH}_{2}$ (citronella) \\
\hline- & $2880^{\text {sh }}$ & $2880^{\mathrm{sh}}$ & Symmetric stretch $\mathrm{CH}_{2}$ (glycerol) \\
\hline 2875 & 2875 & 2875 & Symmetric stretch $\mathrm{CH}_{3}$ \\
\hline- & - & $2872^{\text {sh }}$ & Symmetric stretch $\mathrm{CH}_{3}$ (citronella) \\
\hline- & - & $2856^{\mathrm{sh}}$ & Symmetric stretch $\mathrm{CH}_{2}$ (citronella) \\
\hline 2853 & 2853 & 2853 & Symmetric stretch $\mathrm{CH}_{2}$ \\
\hline - & - & 1725 & $\mathrm{C}=\mathrm{O}$ stretch (citronella) \\
\hline 1627 & 1630 & 1630 & Amide I, $\mathrm{C}=\mathrm{O}$ stretch/hydrogen bond coupled with $\mathrm{COO}^{-}$ \\
\hline 1539 & 1545 & 1545 & Amide II, NH bond coupled with $\mathrm{CN}$ stretch \\
\hline 1450 & 1450 & 1450 & $\mathrm{CH}_{2}$ bend \\
\hline 1401 & 1401 & 1401 & C-O symmetric stretch carboxyl group \\
\hline- & - & $1377^{\text {sh }}$ & $\mathrm{CH}_{3}$ bend (citronella) \\
\hline 1334 & 1334 & 1334 & $\mathrm{CH}_{2}$ wagging \\
\hline 1237 & 1237 & 1237 & Amide III, C-O stretch \\
\hline- & 1034 & 1034 & OH bend (glycerol) \\
\hline 1030 & $1030^{\text {sh }}$ & $1030^{\text {sh }}$ & Skeletal stretch \\
\hline
\end{tabular}

sh: shoulder 
Table 2

\begin{tabular}{|l|c|c|c|c|c|c|c|}
\hline $\begin{array}{l}\text { Predominant } \\
\text { conformation }\end{array}$ & $\begin{array}{c}\text { Frequency range } \\
\left(\mathbf{c m}^{-1}\right)\end{array}$ & \multicolumn{2}{|c|}{ A } & \multicolumn{2}{c|}{ AG } & \multicolumn{2}{c|}{ AGC } \\
\hline & & unaged & light aged & unaged & light aged & unaged & light aged \\
\hline$\beta$-sheet & $1611-1640,1690$ & 54 & 54 & 48 & 44 & 48 & 46 \\
\hline Random coil, helical & $1641-1659$ & 18 & 21 & 26 & 32 & 27 & 26 \\
\hline Triple Helical & 1660 & 19 & 13 & 16 & 14 & 15 & 15 \\
\hline Turns & $1662-1689$ & 9 & 12 & 10 & 10 & 10 & 13 \\
\hline
\end{tabular}


Table 3

\begin{tabular}{|c|c|c|c|c|c|c|}
\hline Peak & Compound & $\underset{(\mathbf{m i n})}{\mathbf{R}_{\mathbf{t}}}$ & $\mathbf{m} / \mathbf{z}$ & $\mathbf{M}_{\mathbf{w}}$ & $\mathbf{C}$ & C-UV \\
\hline 2 & 2-propanone & 1.64 & $\underline{31,43,58}$ & 58 & $\sqrt{ }$ & $\sqrt{ }$ \\
\hline 4 & $\alpha$-thujene & 5.46 & $\overline{77,91,93}, 136$ & 136 & $\sqrt{ }$ & $\sqrt{ }$ \\
\hline 5 & $\alpha$-pinene & 5.56 & $77,79,91, \underline{93}$ & 136 & $\sqrt{ }$ & $\sqrt{ }$ \\
\hline 6 & Camphene & 5.77 & $79, \underline{93}, 107,121$ & 136 & $\sqrt{ }$ & $\sqrt{ }$ \\
\hline 9 & 6-methyl-5-hepten-2-one & 6.18 & $43,55,69, \overline{108}$ & 126 & $\sqrt{ }$ & $\sqrt{ }$ \\
\hline 10 & $\alpha$-myrcene & 6.23 & $41, \underline{69}, 93,95$ & 136 & $\sqrt{ }$ & $\sqrt{ }$ \\
\hline 11 & $\alpha$-phellandrene & 6.43 & $77, \underline{93}, 136$ & 136 & $\sqrt{ }$ & $\sqrt{ }$ \\
\hline 12 & 1-methyl-4-(1-methylethyl)-benzene & 6.67 & $77,91,119,134$ & 134 & $\sqrt{ }$ & $\sqrt{ }$ \\
\hline 13 & dl-limonene & 6.74 & $\underline{68}, 79,93,121$ & 136 & $\sqrt{ }$ & $\sqrt{ }$ \\
\hline 18 & Linalool & 7.51 & $41,55, \underline{71}, 93$ & 154 & $\sqrt{ }$ & $\sqrt{ }$ \\
\hline 19 & $\beta$-pinene oxide & 7.63 & $41,67,82,123$ & 152 & - & $\sqrt{ }$ \\
\hline 20 & Tetrahydro-4-methyl-2-(2-methylpropenyl)-2H pyran & 7.65 & $41,69,83,139$ & 154 & $\sqrt{ }$ & $\sqrt{ }$ \\
\hline 21 & Citronellal & 8.14 & $41,69,95, \overline{121}$ & 154 & $\sqrt{ }$ & $\sqrt{ }$ \\
\hline 22 & Isopulegol & 8.28 & $41, \overline{69}, 84,121,136$ & 154 & $\sqrt{ }$ & $\sqrt{ }$ \\
\hline
\end{tabular}




\begin{tabular}{|c|c|c|c|c|c|c|}
\hline 23 & 5-methylcyclohexanone & 8.33 & $69,112,139,154$ & 154 & - & $\sqrt{ }$ \\
\hline 24 & Isopulegol 2 & 8.38 & $41,69, \underline{81}, 95,121$ & 154 & $\sqrt{ }$ & $\sqrt{ }$ \\
\hline 25 & $\alpha$-terpineol & 8.55 & $\underline{59}, 93,121,136$ & 154 & $\sqrt{ }$ & $\sqrt{ }$ \\
\hline 26 & 2-decen-1-ol & 8.62 & $41, \underline{57}, 70,82$ & 156 & $\sqrt{ }$ & $\sqrt{ }$ \\
\hline 27 & $\beta$-citronellol & 8.89 & $41, \underline{69,81,95}$ & 156 & $\sqrt{ }$ & $\sqrt{ }$ \\
\hline 28 & $\beta$-citral & 9.03 & $\underline{41,69,94,109}$ & 152 & $\sqrt{ }$ & $\sqrt{ }$ \\
\hline 29 & Geraniol & 9.23 & $41, \underline{69}, 93,123$ & 152 & $\sqrt{ }$ & $\sqrt{ }$ \\
\hline 30 & $\alpha$ - citral & 9.32 & $41, \underline{69}, 84,109$ & 152 & $\sqrt{ }$ & $\sqrt{ }$ \\
\hline 31 & Citronellyl formate & 9.34 & $\underline{41,55,69,81,95}$ & 184 & $\sqrt{ }$ & $\sqrt{ }$ \\
\hline 32 & Geraniol formate & 9.57 & $41, \underline{69}, 93,136$ & 182 & $\sqrt{ }$ & $\sqrt{ }$ \\
\hline 33 & Citronellic acid & 9.69 & $41,55, \underline{69}, 95,110$ & 170 & $\sqrt{ }$ & $\sqrt{ }$ \\
\hline 34 & Pulegone & 9.86 & $41,67, \underline{81}, 109$ & 158 & $\sqrt{ }$ & $\sqrt{ }$ \\
\hline 35 & 2-(2-hydroxy-2-propyl)-5-methyl-cyclohexanol & 9.98 & $43,59, \underline{81}, 96$ & 172 & $\sqrt{ }$ & $\sqrt{ }$ \\
\hline 36 & Citronellyl acetate & 10.04 & $\underline{43}, 69,81,95$ & 198 & $\sqrt{ }$ & $\sqrt{ }$ \\
\hline 37 & Eugenol & 10.17 & $103,131,149,164$ & 164 & $\sqrt{ }$ & $\sqrt{ }$ \\
\hline 38 & Geraniol acetate & 10.33 & $41, \underline{69}, 93,121$ & 196 & $\sqrt{ }$ & $\sqrt{ }$ \\
\hline 39 & $\beta$-Elemene & 10.51 & $68,81,93,107$ & 204 & $\sqrt{ }$ & $\sqrt{ }$ \\
\hline 40 & $\beta$-Cubebene & 10.79 & $91,105,120, \underline{161}$ & 204 & $\sqrt{ }$ & $\sqrt{ }$ \\
\hline 41 & Cariophyllene & 10.83 & $41, \underline{69}, 93,133$ & 204 & $\sqrt{ }$ & $\sqrt{ }$ \\
\hline 42 & $\mathrm{v}$-Cadinene & 10.87 & $91,105,119, \underline{161}$ & 204 & $\sqrt{ }$ & $\sqrt{ }$ \\
\hline 43 & $\begin{array}{l}\text { Naphthalene, 1,2,3,4,4a,5,6,8a-octahydro-7-methyl-4-methylene-1-(1- } \\
\text { methylethyl)-/germacrene-D }\end{array}$ & 11.01 & $81,91,119,161$ & 204 & $\sqrt{ }$ & $\sqrt{ }$ \\
\hline 44 & Trans- $\alpha$-bisabolene & 11.11 & $80, \underline{93}, 121,161$ & 204 & $\sqrt{ }$ & $\sqrt{ }$ \\
\hline 45 & v-muurolene & 11.26 & $105,119, \underline{161}, 204$ & 204 & $\sqrt{ }$ & $\sqrt{ }$ \\
\hline 46 & Germacrene D & 11.34 & $105,119, \underline{161}, 204$ & 204 & $\sqrt{ }$ & $\sqrt{ }$ \\
\hline 47 & $\alpha$-muurolene & 11.45 & $91, \underline{105}, 161,204$ & 204 & $\sqrt{ }$ & $\sqrt{ }$ \\
\hline 48 & $\alpha$-cadinene & 11.59 & $105,119, \underline{161}, 204$ & 204 & $\sqrt{ }$ & $\sqrt{ }$ \\
\hline 49 & $\delta$-cadinene & 11.66 & $119,134, \underline{161}, 204$ & 204 & $\sqrt{ }$ & $\sqrt{ }$ \\
\hline
\end{tabular}




\begin{tabular}{|c|c|c|c|c|c|c|}
\hline 50 & 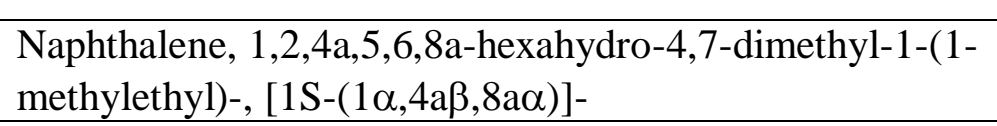 & 11.78 & $105,161,189,204$ & 204 & $\sqrt{ }$ & $\sqrt{ }$ \\
\hline 51 & Elemol & 11.86 & $\underline{59}, 93,161,189$ & 222 & $\sqrt{ }$ & $\sqrt{ }$ \\
\hline 52 & Germacrene D-4-ol & 12.12 & $43,81,123,161$ & 222 & $\sqrt{ }$ & $\sqrt{ }$ \\
\hline 53 & $\tau$-Eudesmol & 12.56 & $43,161,189,204$ & 222 & $\sqrt{ }$ & $\sqrt{ }$ \\
\hline 54 & $\tau$-cadinol & 12.61 & $43,105,161,204$ & 222 & $\sqrt{ }$ & $\sqrt{ }$ \\
\hline 55 & $\alpha$-cadinol & 12.73 & $\underline{43}, 95,121,204$ & 222 & $\sqrt{ }$ & $\sqrt{ }$ \\
\hline 56 & Dimer & 14.99 & $41,69,81,95$ & 290 & - & $\sqrt{ }$ \\
\hline 57 & Dimer & 15.09 & $41,55, \underline{69}, 109$ & 290 & $\sqrt{ }$ & $\sqrt{ }$ \\
\hline 58 & Dimer & 15.14 & $41,55,69,95$ & 222 & - & $\sqrt{ }$ \\
\hline 59 & Dimer & 15.19 & $41, \underline{69}, 109,121$ & 290 & - & $\sqrt{ }$ \\
\hline 60 & Dimer & 15.36 & $41, \underline{69}, 95,121$ & 288 & - & $\sqrt{ }$ \\
\hline 61 & Dimer & 15.45 & $\underline{69,81,95,137}$ & 306 & - & $\sqrt{ }$ \\
\hline 62 & Dimer & 15.62 & $41,69,81,95$ & 308 & - & $\sqrt{ }$ \\
\hline 63 & Dimer & 15.71 & $41, \underline{69}, 81,95$ & 306 & - & $\sqrt{ }$ \\
\hline 64 & Dimer & 15.74 & $41, \underline{69}, 81,109$ & 308 & - & $\sqrt{ }$ \\
\hline 65 & Farnesol isomer $\beta$ & 15.76 & $41,69,81,95$ & 222 & $\sqrt{ }$ & - \\
\hline 66 & Farnesol isomer $\alpha$ & 15.79 & $41, \underline{69,81,93}$ & 222 & $\sqrt{ }$ & - \\
\hline 67 & Dimer & 15.81 & $41, \underline{69,81,95}$ & 308 & - & $\sqrt{ }$ \\
\hline 68 & Dimer & 15.87 & $41, \underline{69}, 81,109$ & 308 & - & $\sqrt{ }$ \\
\hline 69 & Dimer & 15.91 & $41,69,81,109$ & 306 & - & $\sqrt{ }$ \\
\hline 70 & Dimer & 15.98 & $41, \underline{69}, 95,109$ & 310 & - & $\sqrt{ }$ \\
\hline 71 & Dimer & 16.08 & $41, \underline{69}, 95,109$ & 310 & - & $\sqrt{ }$ \\
\hline 72 & Dimer & 16.23 & $41, \underline{69}, 81,109$ & 310 & - & $\sqrt{ }$ \\
\hline 73 & Dimer & 16.32 & $41, \underline{69}, 95,109$ & 310 & - & $\sqrt{ }$ \\
\hline
\end{tabular}


Table 4.- Mean value and standard deviation of elastic modulus, water vapor permeability (WVP), water solubility (WS), and water content (WC) obtained in the studied specimens.

\begin{tabular}{|c|c|c|c|c|}
\hline Series & $\begin{array}{c}\text { Elastic Modulus } \\
(\mathbf{M P a} / \mathbf{m m})\end{array}$ & $\begin{array}{c}\text { WVP } \\
\left(\mathbf{g . m} / \mathbf{m}^{2} . \mathbf{P a} . \mathbf{d a y}\right)\end{array}$ & $\begin{array}{c}\text { WS } \\
(\mathbf{\%})\end{array}$ & $\begin{array}{c}\text { WC } \\
(\mathbf{\%})\end{array}$ \\
\hline A & $14000 \pm 3000$ & $2.0 \times 10^{-5} \pm 4 \times 10^{-6}$ & $20.2 \pm 1.1$ & $14.5 \pm 0.2$ \\
\hline A-UV & $14000 \pm 3000$ & $1.7 \times 10^{-5} \pm 2 \times 10^{-6}$ & $11.1 \pm 0.9$ & $14.7 \pm 0.3$ \\
\hline AG & $65 \pm 10$ & $2.4 \times 10^{-5} \pm 5 \times 10^{-6}$ & $23.1 \pm 1.5$ & $24.5 \pm 0.7$ \\
\hline AG-UV & $54 \pm 4$ & $2.3 \times 10^{-5} \pm 6 \times 10^{-6}$ & $20.3 \pm 1.5$ & $23.3 \pm 0.6$ \\
\hline AGC & $16 \pm 2$ & $3.7 \times 10^{-5} \pm 4 \times 10^{-6}$ & $26.6 \pm 1.5$ & $22.8 \pm 0.5$ \\
\hline AGC-UV & $21 \pm 1$ & $3.2 \times 10^{-5} \pm 6 \times 10^{-6}$ & $18.5 \pm 1.5$ & $21.5 \pm 0.5$ \\
\hline
\end{tabular}




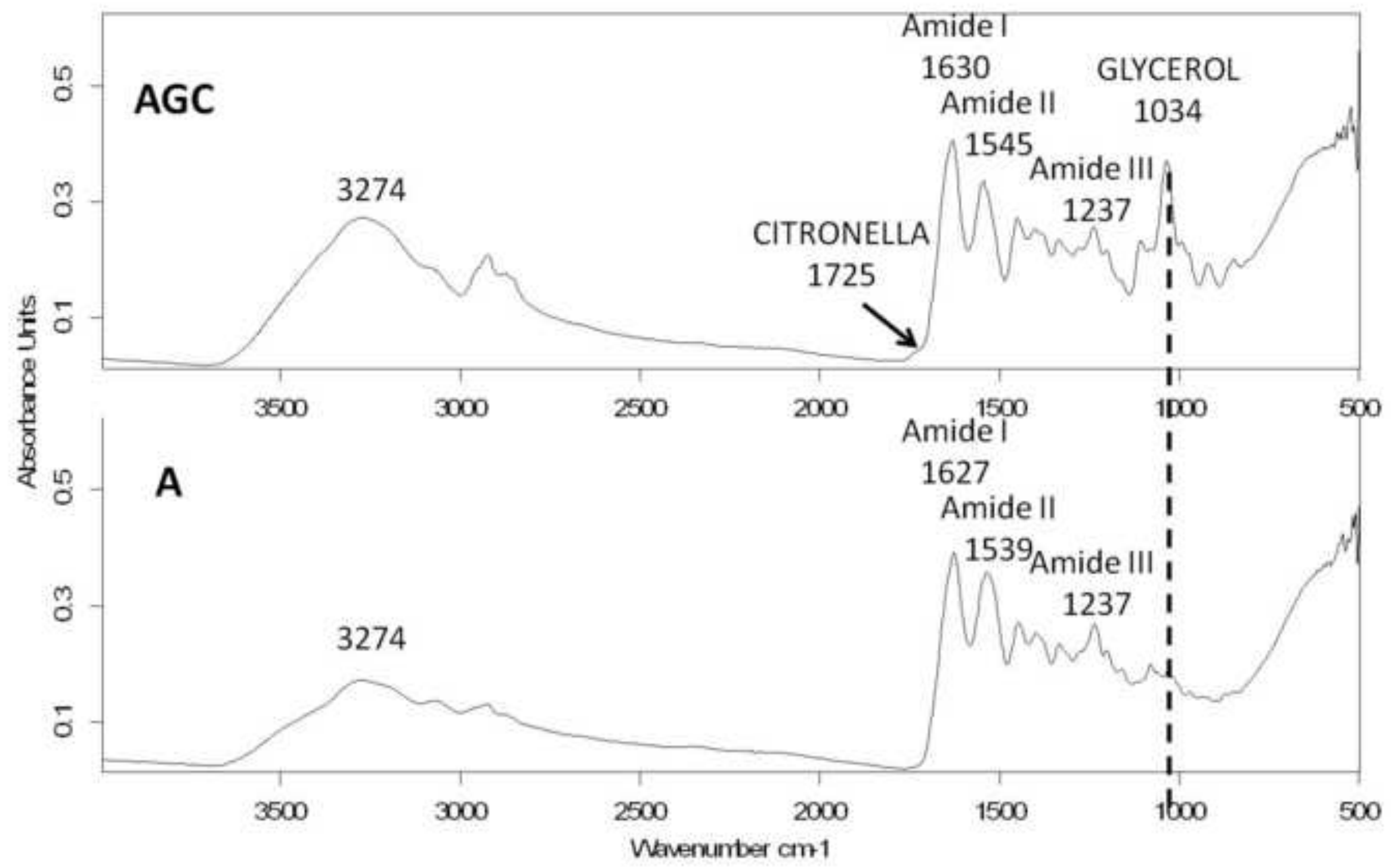




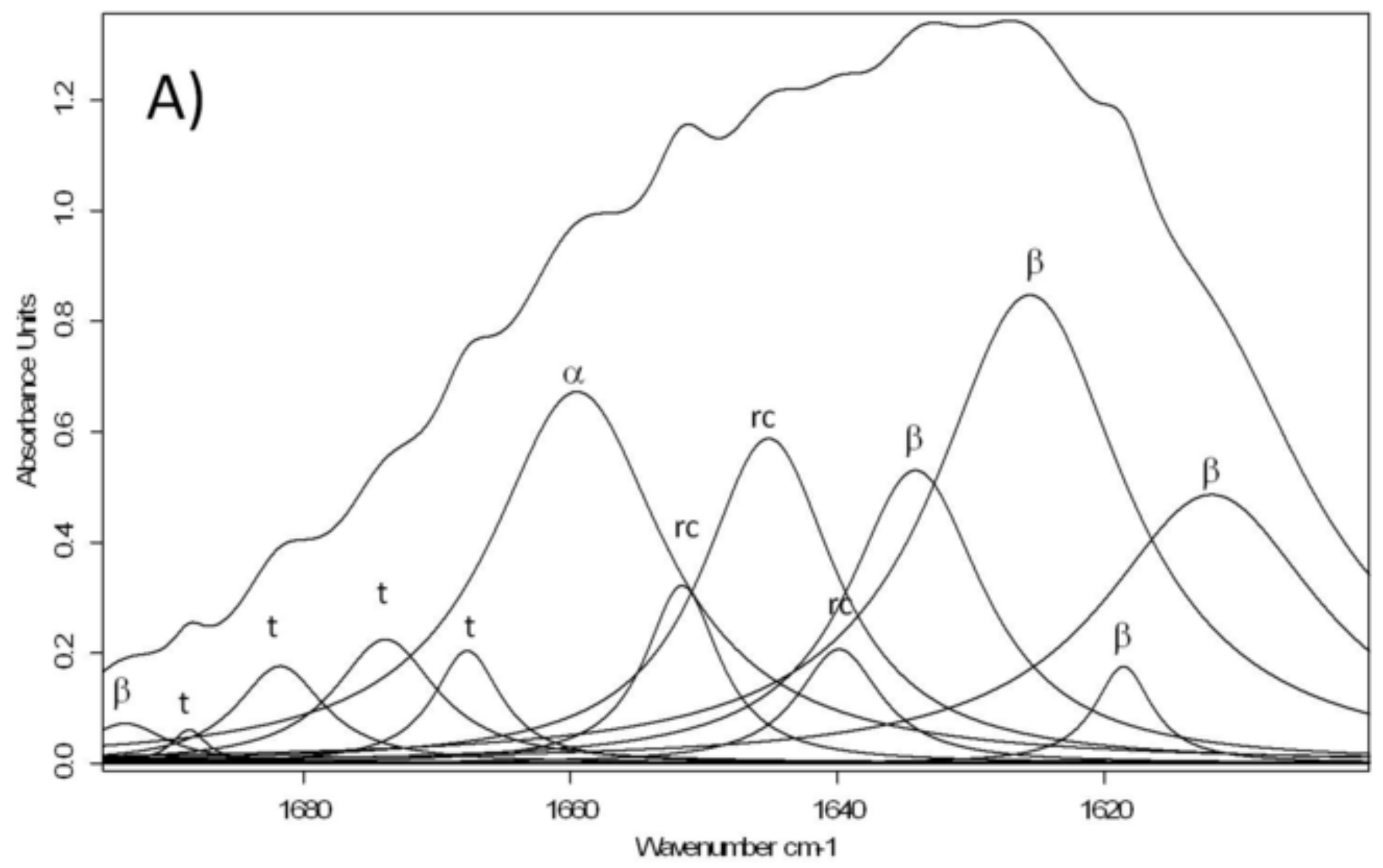




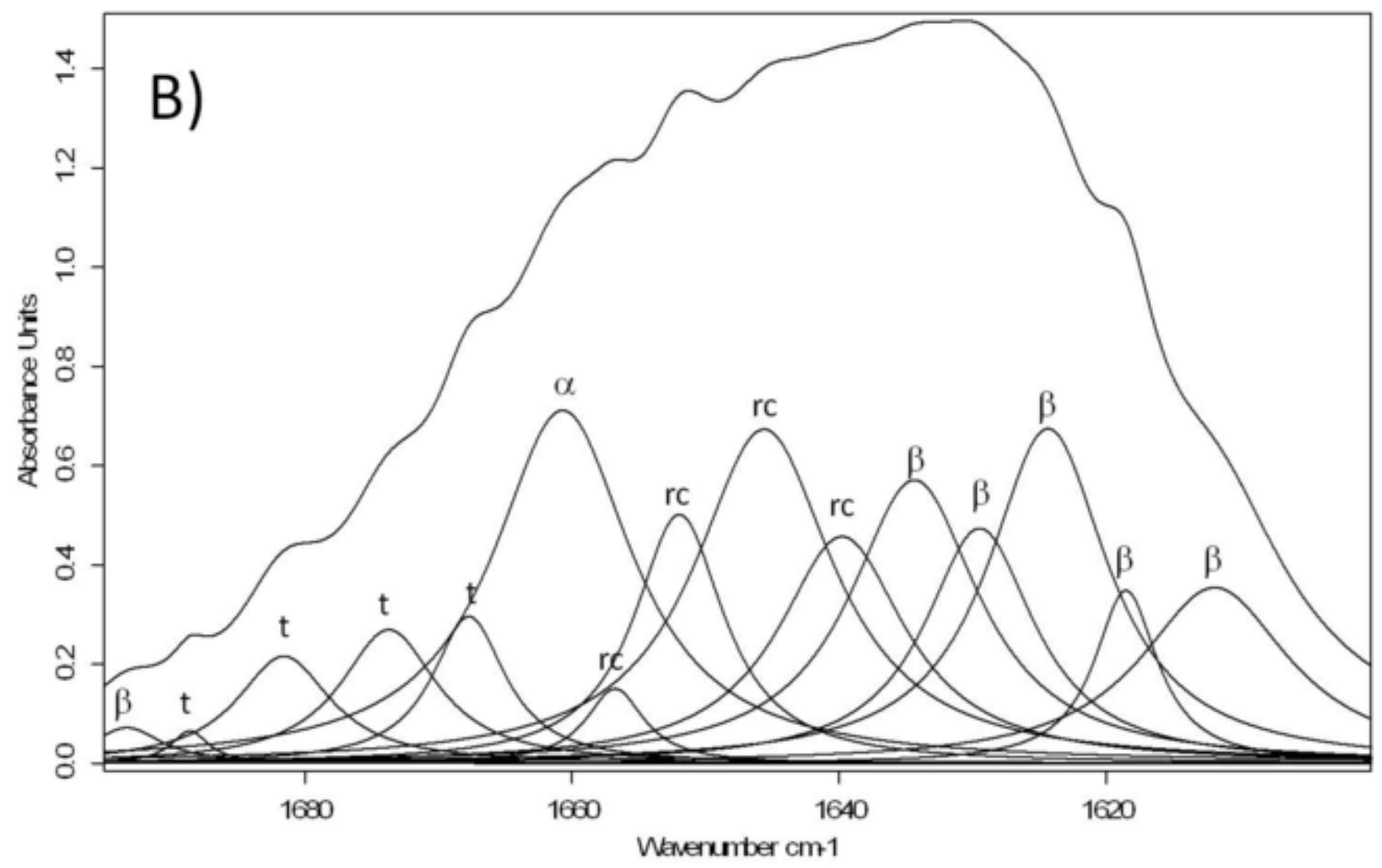




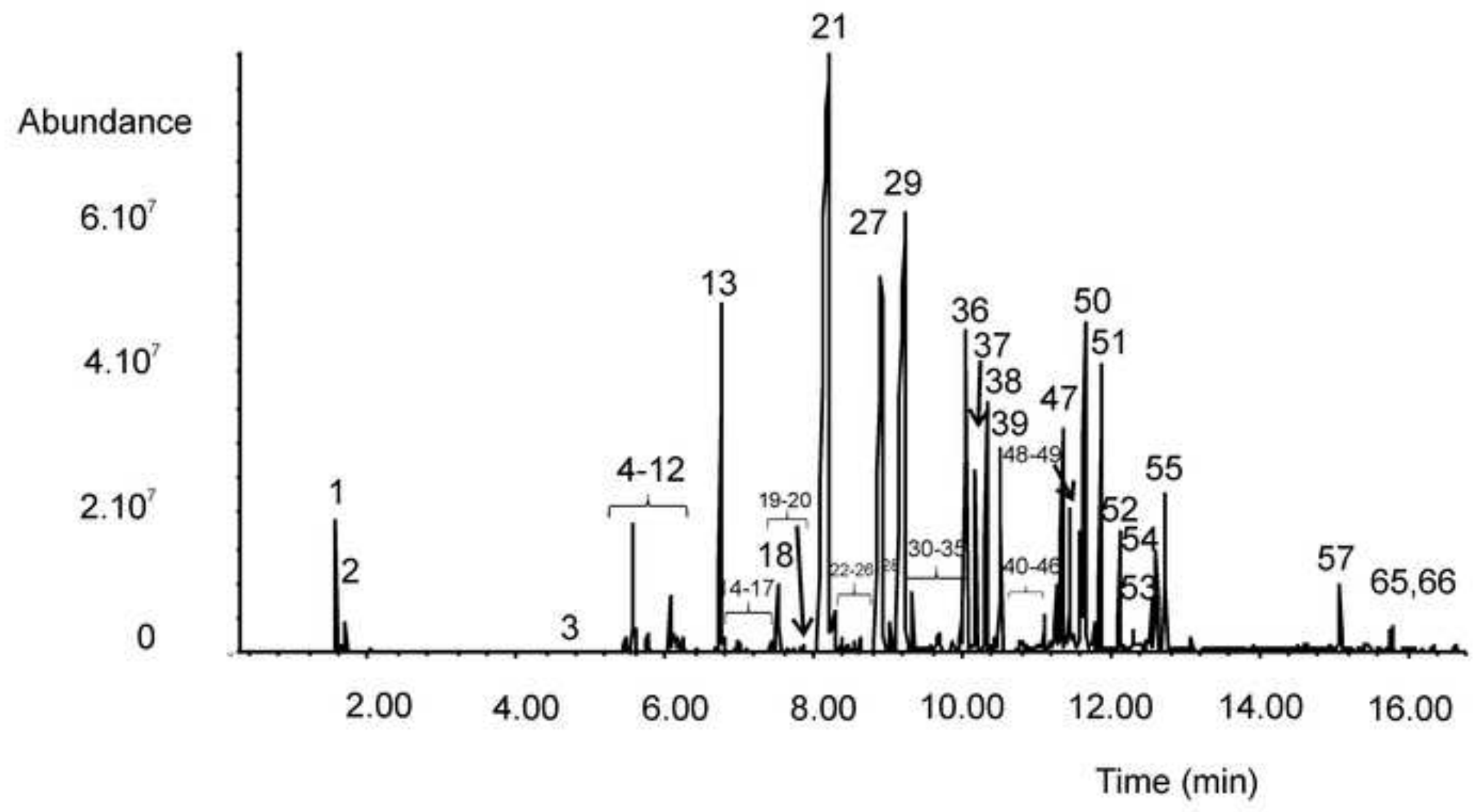




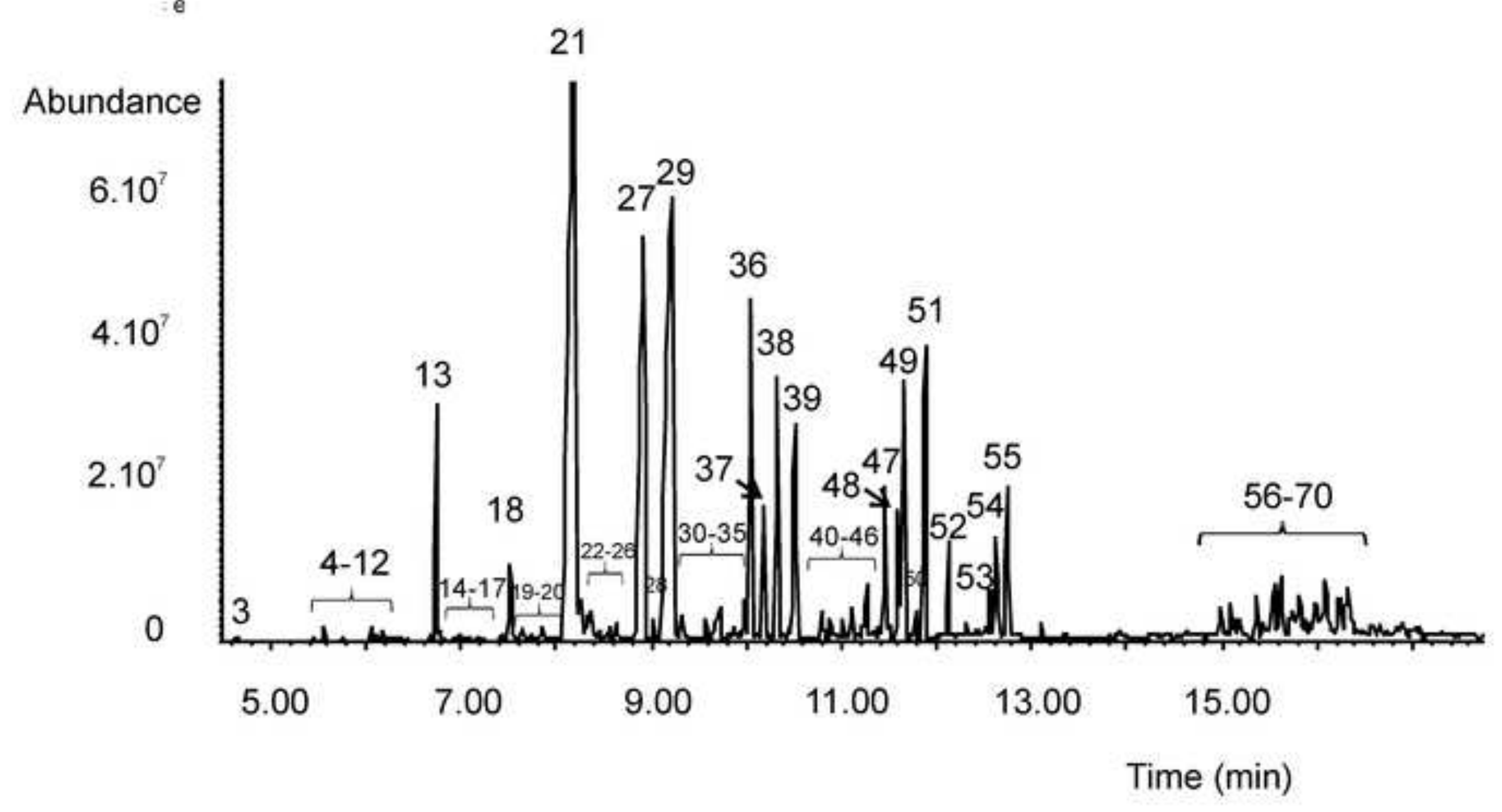


Click here to download high resolution image
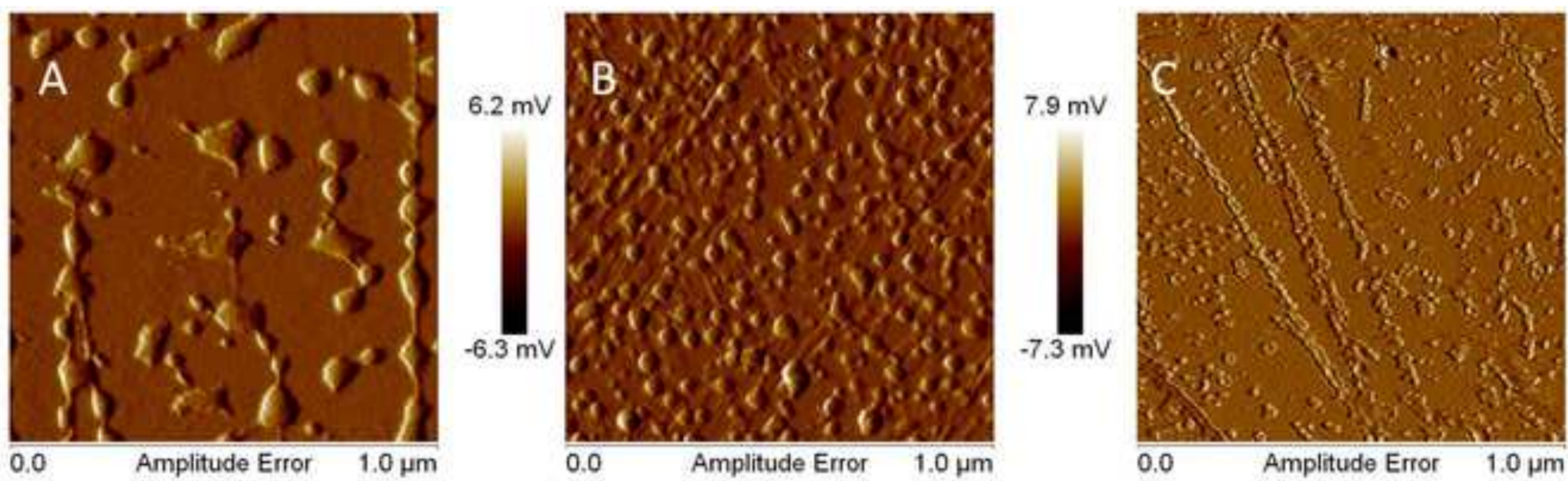

$7.2 \mathrm{mV}$

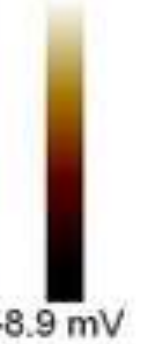



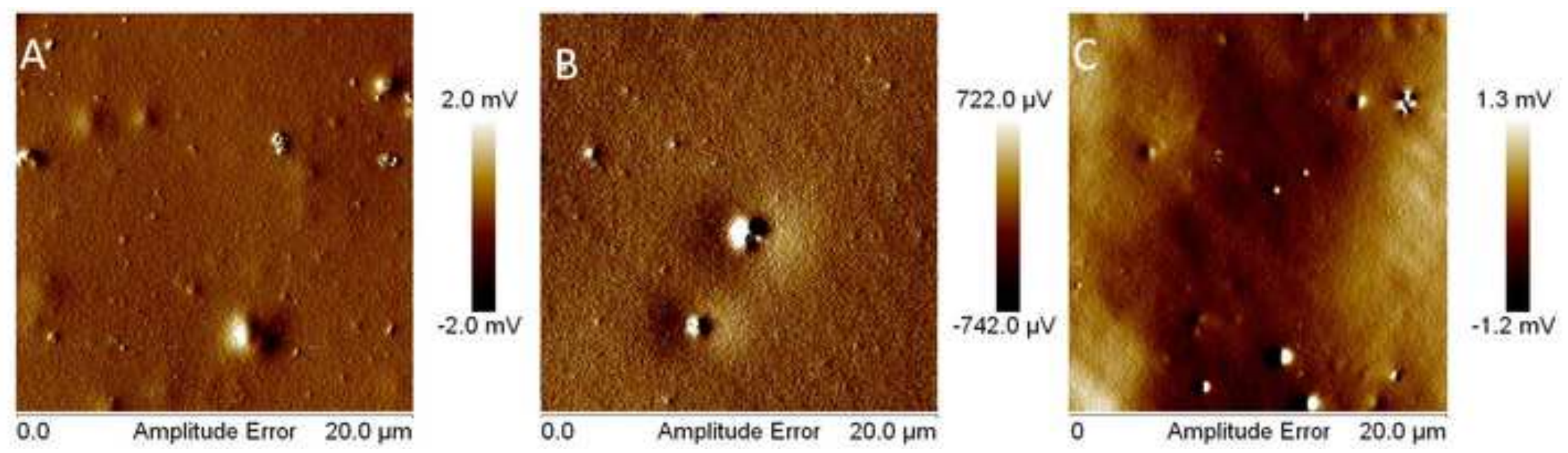


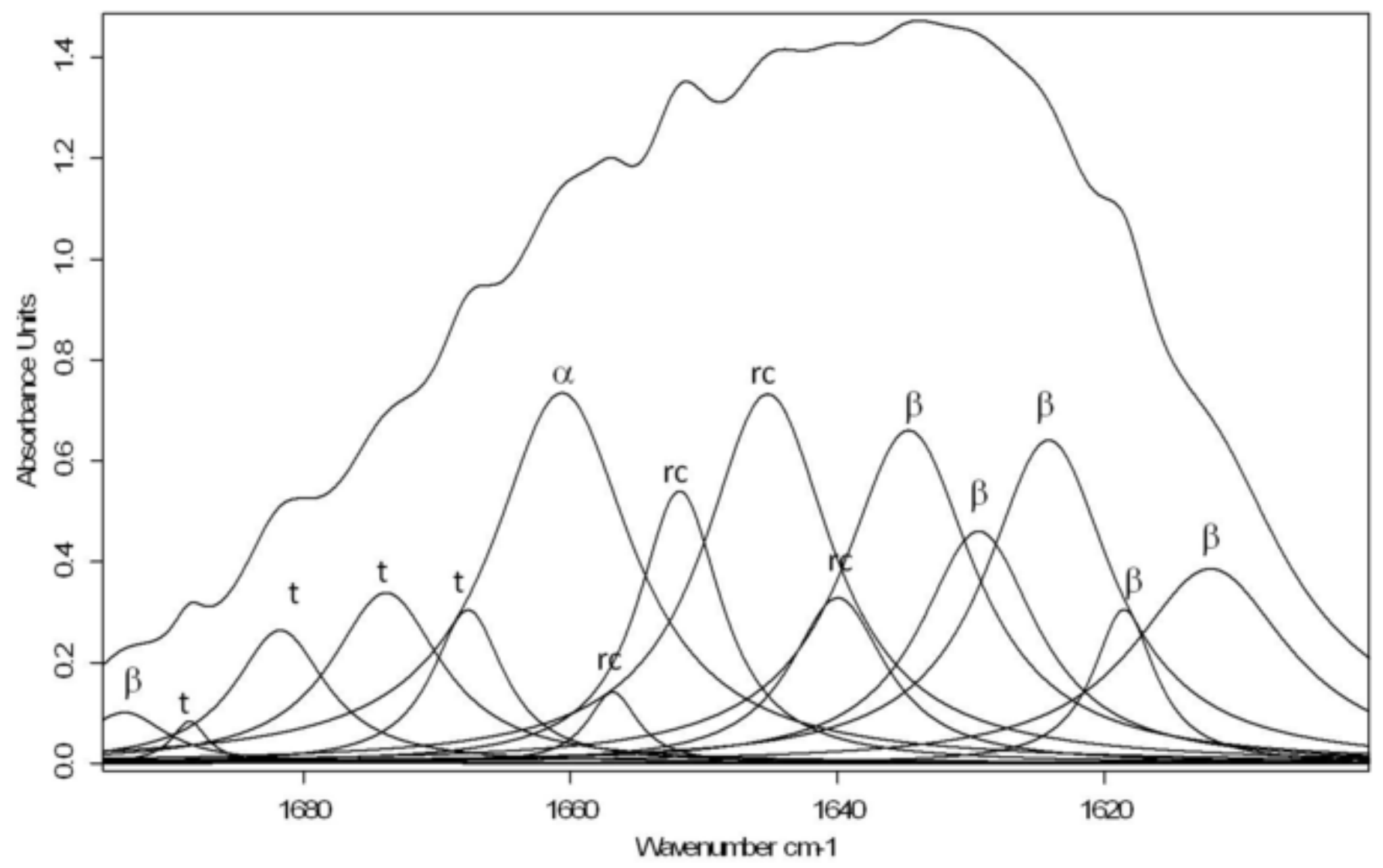

